\title{
Changes in Qualities Valued in Children in the United States, 1964 to 1984
}

\author{
Duane F. Alwin \\ Institute for Social Research and Department of Sociology, University of Michigan
}

This paper examines changes that have occurred over the past few decades in parental assessments of qualities valued in children. Data are examined from eight NORC national surveys to assess the degree of change experienced in these parental values, and several explanations are considered for the observed changes. The major finding of this research supports earlier observations regarding changes in parental values. Those child qualities generally thought to be associated with obedience or conformity (to obey parents, to have good manners, to be neat and clean, and to act according to sex-role norms) are seen to have declined in importance, and the qualities generally associated with autonomy or self-direction (good sense and sound judgement, honesty, responsible, and considerate) have increased in their assessed importance to parents during this period. The potential sources of these changes are considered, and several explanations are examined. The results of these considerations suggest that changes in levels of schooling, a primary antecedent of parental autonomy versus conformity values, explains some of the change, and there appears to be support for the role of other cohort-related or "generational" factors. The results also provide evidence, as hypothesized, that an important source of change in parental autonomy vs. conformity values over this period is among persons of Catholic background, especially those persons born after the Great Depression. ๑ 1989 Academic Press, Inc.

Over the past several centuries in industrial Western societies, the relationships within the nuclear family, especially those between parents and their children, have changed in important ways. This change has generally been in the direction of the greater expression of affection toward children and a greater interest in their development (Stone, 1977;

This is the basis for part of a paper presented at the 1988 annual meeting of the American Sociological Association, held in Atlanta, GA. This research was supported in part by grant funds from the National Institute of Mental Health (MH37289, MH39761). I acknowledge the Inter-University Consortium for Political and Social Research for providing access to the data from the General Social Surveys, and Melvin L. Kohn, Carmi Schooler, and Carrie Schoenbach for their assistance in providing the 1964 NIH-NORC data. I also acknowledge the assistance of Lynn Dielman, Evelyn Caviani, and Susan Sherry in data analysis and manuscript preparation. 
Schlumbohm, 1980; Vinovskis, 1987). During the 18th and 19th centuries, parents, especially those members of the middle- and upper-classes, increasingly treated children as if they were of greater value than was the case in earlier centuries. For instance, these changes are reflected in significant declines in fertility and infant mortality (Stone, 1977), and changes in legal and social practices with respect to the value of children (Zelizer, 1985).

In the modern era children's lives became relatively more controlled by adult society, more affection and other resources were devoted to their development, and serious consideration was given to modes of childrearing. Variations in these elements of society seem to have undergone considerable change over the past few centuries, especially the preferred modes of producing child development. Several studies have presented evidence in support of the conclusion that significant changes have occurred in parental values over various parts of the 20th century. For example, evidence exists from surveys conducted in the Detroit metropolitan area since 1958 (Duncan, Schuman, and Duncan, 1973; Duncan, Duncan, and McRae, 1978; Duncan, 1985; Alwin, 1984, 1986), and from data assembled on Muncie, Indiana, from the Middletown studies between 1924 and 1978 (Caplow and Chadwick, 1979; Bahr, 1980; Caplow et al., 1982; Alwin, 1988), that parental values increasingly reflect desires for autonomy or independence in children and decreasingly a desire for conformity or obedience. And, using data from two NORC national surveys, Wright and Wright (1976) presented evidence suggesting that in the decade between 1964 and 1973 men had changed in the direction of greater preferences for autonomy or self-direction in children and a lesser emphasis on obedience (cf. Kohn, 1976).

The study by Wright and Wright (1976) is, to my knowledge, the only existing national U.S. study of trends in parental values. Despite its considerable merit, that study spanned barely a single decade, and it is not known whether the observed trends have continued into the decade of the 1980s. And, given the possible limits to generalizability from data based on the regional and local samples referred to above, it is not completely clear whether research results from such samples portray trends that exist in the nation as a whole, or whether these patterns are tied to unique historical experiences of persons living in a particular region (or city) at one particular historical time.

In order to verify the presence of these trends in more broadly based samples available for the more recent past, the present study builds upon these lines of investigation by using data for both men and women from eight national surveys for the period 1964 to 1984 . These data contain replicate measures of the qualities parents most desire in children. In addition, in order to better understand the nature of these trends I con- 
sider the sources of change in the factors influencing parental values. In so doing, I examine changes in the age and educational composition of the population, and possible sources of changes in societal experiences of religio-ethnic groups during this time period.

\section{VALUE CHANGE SINCE THE 1960S}

As noted in the foregoing, Wright and Wright (1976) assessed changes in parental values using data from Kohn's 1964 national survey of employed men (Kohn, 1969) and data from the 1973 General Social Survey (GSS) (NORC, 1988). ${ }^{1}$ They concluded that the marginal distributions for the 1964 and 1973 measures of parental values were significantly different in many cases, indicating substantial changes over the decade. Specifically, they found that child qualities generally thought to be associated with obedience (to obey parents, good manners, being neat and clean, sex role conformity) declined in importance and the qualities generally associated with autonomy or self-direction (good sense and sound judgement, honesty, responsible, considerate) increased in importance during this period. ${ }^{2}$ For example, the percentage of fathers valuing the quality "obeys parents" as the "most important quality" declined from 23.5 to 13.4 percent over the decade and the quality "good sense and sound judgement" increased in importance from 9.9 to 15.2 percent. Wright and Wright (1976) concluded from the evaluation of these data that they were indicative of "a trend toward less authoritarian or "conformist' values, or alternatively, an overall population increase in the value of self-direction"' (see Wright and Wright, 1976, p. 531).

The Wrights' work was severely criticized by Kohn (1976), who cast doubt on the accuracy of their conclusions. First, Kohn argued, the Wrights' analysis of the 1973 GSS data had not been carried out on a comparable sample (1976, p. 541). The 1964 data were based orr men with children aged 3 through 15 living at home, and Wright and Wright had analyzed data from men living in households where there were children present aged 0-17. Kohn argued that with reference to the 1973 GSS data, "given NORC's way of coding the data," the trend analysis

\footnotetext{
${ }^{1}$ Although the major research monograph reporting the 1964 study was authored by Kohn (1969), I was reminded that Carmi Schooler was a full partner (with Kohn) in planning the 1964 study (Melvin Kohn, Personal Communication, 1/17/89). So, it is with apologies to Carmi Schooler that for the sake of brevity I refer to the 1964 study and the measures developed therein as "Kohn's survey" and later on to "Kohn's measures."

2 Throughout the present paper I use the terms autonomy, self-direction, and independence interchangeably. Autonomy and independence are synonyms, and both incorporate the meaning of self-direction when applied to individuals, i.e., the idea that when individuals govern their own behavior rather than conform to forces outside themselves they are being self-directed (Alwin, 1984, p. 363).
} 
"should be based on men who have children and who live in households where there are children aged 6 through 17," rather than those with children aged 0-17 studied by the Wrights (p. 541). ${ }^{3}$ Further, Kohn contended that the Wrights' assessed change in fathers' values between 1964 and 1973 was suspect because it was based on the analysis of only the most extreme category of valuation, the trait valued most of all, rather than the full range of the "child qualities" variables (see below).

Kohn's own analysis (1976, p. 541) based on a comparison of his data with GSS fathers with children aged 6-17, and an analysis, not of extreme categories but of means, showed that there had indeed been statistically significant changes in fathers' values. However, he argued that the observed changes did not reflect a true increase in self-direction and a decrease in conformity. He argued instead that the qualities changing the most were related to the concept of maturity rather than traits linked to self-direction. The traits changing between 1964 and 1973 which the Wrights (1976) had identified as a change in self-direction were responsibility, good sense and sound judgement, and honesty. These are traits associated with "maturity," argued Kohn, not self-direction.

Kohn (1976, p. 541) concluded from this that there was "no justification for inferring change in parental valuation of self-direction." Rather, the change observed by the Wrights "reflects nothing more than a methodological artifact: parents of somewhat older children, asked what characteristics they value for children of unspecified age, tend to choose those that are appropriate for older children." By contrast, traits less highly valued by fathers in 1973 were acting like a boy or girl should, being obedient, and getting along with other children. These qualities, Kohn asserted (1976, p. 541), "are precisely the characteristics our earlier analysis showed to be more valued for younger children." 4

This, despite the fact that Kohn himself (1969, pp. 193-194) had earlier argued that "a major historical trend probably has been-and will continue to be-toward an increasingly self-directed populace." Kohn cited rising educational levels and increasing levels of occupational self-direction experienced by the labor force. But, theoretical speculation and empirical verification are two different things, and while the theory may be correct, the available data must be further analyzed and interpreted.

\footnotetext{
${ }^{3}$ The Wrights also included some men who were not parents (see Kohn, 1976, p. 541), and this may add some error to assessments of "parental values," but I suspect such biases were trivial.

${ }^{4}$ Kohn (1976) failed to point out, however, that except for the quality "honesty," all of these traits are also correlated with his notion of self-direction. Moreover, another trait. "considerate," which changed between 1964 and 1973 (see Wright and Wright, 1976, p. 531), is also linked to self-direction.
} 


\section{A REEXAMINATION OF CHANGES IN PARENTAL VALUES SINCE 1964}

The Wrights' (1976) hypothesis of social change in parental values deserves further consideration, given the emergence of other data convincingly portraying trends in parental values in these same directions (see Duncan, 1985; Duncan, Schuman, and Duncan, 1973; Duncan, Duncan, and McRae, 1978; Alwin, 1984, 1988), and given the availability of new data on these measures into the decade of the 1980s. For these purposes, I here reanalyze data from the 1964 and 1973 studies, along with other more recently collected data from the General Social Survey (NORC, 1988). I find strong support for the conclusion that parental socialization values have changed since the 1960 s, as concluded by Wright and Wright (1976). ${ }^{5}$ These results are consistent with mounting results that indicate that tremendous changes in attitudes and orientations to the family were experienced during the decade of the 1960 s (see Glenn, 1988; Thornton, 1988). Evidence for change in these directions since the 1970s is more difficult to establish, and there is some indication that the trend might be slowing.

\section{Data and Measures}

The measures used in this debate, and in the present assessment, originated in the early work of Kohn and Pearlin in a study of parental values conducted in Washington, DC, and Turin, Italy (Kohn, 1959, 1969; Pearlin and Kohn, 1966). These survey measures, fashioned after the earlier efforts of Lynd and Lynd (1929) and Duvall (1946) to measure child-rearing orientations, asked parents to consider a list of child qualities or traits potentially desired in children and to produce an ordering of the child qualities in terms of their desirability as qualities "for children to have." ${ }^{6}$ Kohn's results led him to propose a modified version of his original measures of parental values. In his 1964 NORC national survey, after showing them a list of 13 qualities of children, respondents were asked:

a. The qualities listed on this card may all be important, but which

${ }^{5}$ I do not here assess the additional issues raised by the Wright and Wright (1976) work, or by Kohn's (1976) other criticisms. Instead, I focus only on the possible changes in parental values since the 1960 s.

'The procedure used, given below, consists of a "reduced-ranking," since the respondent is asked to place the desired traits in one of five ordered categories (see Alwin and Jackson, 1982a, p. 202). These categories are (1) the least important quality or trait, (2) one of the least, but not the least, important qualities, (3) neither one of the three most or the three least desirable qualities of children, (4) one of the most, but not the most, important qualities, (5) the most important trait for a child to have (see Kohn, 1969, p. 48). 
three would you say are the most desirable for a (boy/girl) of (child's) age to have?

1. That he has good manners.

2. That he tries hard to succeed.

3. That he is honest.

4. That he is neat and clean.

5. That he has good sense and sound judgement.

6. That he has self-control.

7. That he acts like a boy (she acts like a girl) should.

8. That he gets along well with other children.

9. That he obeys his parents well.

10. That he is responsible.

11. That he is considerate of others.

12. That he is interested in how and why things happen.

13. That he is a good student.

b. Which one of these three is the most desirable of all?

c. All of the qualities listed on this card may be desirable, but could you tell me which three you consider least important?

d. And which one of these three you consider least important?

Kohn asked respondents these questions with regard to a specific one of their children.?

In 1973 an adaptation of these questions was included in the General Social Survey, wherein the question was asked with reference to children in general, and this modified version of the questions (or some variant) has been asked in 8 of the 12 years surveyed by the GSS between 1972 and 1987 (NORC, 1988). ${ }^{8}$ For present purposes we use data from the

\footnotetext{
${ }^{7}$ There are several possible indicators of parental values, based on responses to these questions. One approach is to compare the traits in terms of question (a), which assess the extent to which the population considers the trait one of three most important. A second approach is to compare responses to question $(b)$, which is the stategy followed by Wright and Wright (1976, p. 531). A third possibility is to examine the mean scores on a scale, as follows: $5=$ the most important quality, $4=$ one of the three most important qualities, but not the most important quality, $3=$ neither one of the three most or three least important qualities, 2 = one of the three least important, but not the least important, quality, 1 = the least important trait (Kohn, 1969, p. 48). In the analysis presented below, I make use of all of these indicators.

${ }^{8}$ Since the GSS is a survey concerning public attitudes and not a study of child-rearing per se, the GSS questions must by necessity refer to "a child" in general rather than a child of a specific age and sex, as in Kohn's studies. Because of this there may appear to be a sex-bias in responses to these questions, in that the qualities (with the exception of number 7) are all preceded by the male pronoun "he" rather than a more gender-neutral
} 
$1973,1975,1976,1978,1980,1983$, and 1984 surveys. ${ }^{9}$ To both adequately assess trends over this period and represent relevant subpopulations, in some of the present analyses I combine data from adjacent survey years. In some instances I combine data from the 1973 and 1975 surveys to represent the early 1970s, I combine the 1976 and 1978 data to represent the late 1970s, and I combine the 1980, 1983, and 1984 data to represent the early 1980s. In all instances I exclude cases for which there is incomplete data on the above series of questions. This results in samples of approximately equal size, with representation of both men and women at each of these three time-points, 1973-1975, 1976-1978, and 19801984.

All surveys used here were conducted by NORC, and all were national in scope. ${ }^{10}$ The 1964 study focused on males, 16 years of age or older, working at least $25 \mathrm{hr}$ a week (Kohn, 1969, p. 237). Measures of parental values were obtained from men with children 3 through 15 years of age $(1969$, p. 238). The GSS data are based on the total noninstitutionalized English-speaking population of the continental United States, 18 years of age or older. ${ }^{11}$ However, due to the manner in which the GSS information about children living in the household is coded, it is not possible to match the GSS samples exactly to Kohn's men in terms of the ages of their children. ${ }^{12}$ In short, the GSS records the number of children in

form. However, contrary to this expectation, Schaeffer (1982) shows that there is little difference in mean rankings assigned these qualities in experimental forms comparing the "he" form with the use of the more generic "a child" form. Thus, the questions assess the qualities adults prefer in children in general, regardless of the age and sex of the child. This is a somewhat different question than that studied by Kohn $(1959,1969)$, but it is sufficient for present purposes.

${ }^{9}$ In the 1984 survey, an experiment in response order effects was undertaken which reversed the order of the traits on the above list (see Krosnick and Alwin, 1987), and in the 1986 survey the use of the Kohn questions inadvertently preserved the reversed order of traits. Since there are order effects in these experimental subsamples, I do not include the 1984 and 1986 data involving the reversed order of traits.

"Given the possibility of "house" effects, it is not insignificant that NORC conducted the field work on the two studies. These studies are therefore presumably even more comparable than would otherwise be the case, given similarities in sampling design, questionnaire format, interviewer training, and general field procedures that are known to affect the overall quality of survey data. Thus, in order to emphasize this methodological comparability of the two studies I later refer to the 1964 survey as the Kohn-NORC data.

"See NORC (1988) for details regarding sampling design and response rates and for information regarding the measurement procedures.

${ }^{12}$ In fact, it is difficult to determine the appropriate population for comparative purposes because of the potential age differences of the two samples. Without a control for age there is undoubtedly some error of unknown magnitude in the following comparisons. There is reason to believe, however, that if developmental patterns in parental values, i.e., those correlated with the age of children, are generally monotonic, then on average a comparison of men with children aged 3-15 would be very similar to men with children aged 0-17, ceteris paribus. 
the household in the following categories: aged 0-5, aged 6-12, and aged 13-17. Thus, in order to approximate comparable populations, it becomes necessary to perform analyses using several different approaches.

\section{Adequacy of Measurement}

The above measures have certain limitations with respect to assessing changes in parental values, which must be acknowledged at the beginning of this analysis. The Kohn measures may not be adequate for these purposes in at least three ways. First, as our research has shown (see Alwin and Krosnick, 1985; Krosnick and Alwin, 1987), these measures are very complex and difficult for many respondents. About $10 \%$ of the sample typically does not complete the ranking task, presumably because of its extreme difficulty. Moreover, the responses of those that do are sometimes affected by the order in which responses choices are offered, suggesting the fact that responses are somewhat crude indications of the phenomena of interest. ${ }^{13}$ Second, while these measures do seem to adequately represent the concept of obedience employed here and in previous analyses of trends in parental values (e.g., Alwin, 1984, 1986, 1988), it is not completely clear that these measures validly reflect the qualities associated with autonomy, as defined here. The quality "obeys parents well" precisely assesses the aspect of parental values associated with obedience or conformity. On the other hand, the crucial quality associated with autonomy, for present purposes, involves the idea of parental preferences for independence of children-their exercise of autonomous behavior and decision-making, essentially "to think for themselves." While this aspect of autonomy or self-direction is represented to some extent in Kohn's list of qualities by the traits "good sense and sound judgement," responsible," and "considerate," these traits do not completely encompass the notion of independent thinking. Thus, these qualities only partially reflect the concept of interest. ${ }^{14}$ While the above listed traits reflect developmental outcomes associated with autonomous children, none explicitly refer to "thinking for oneself." ${ }^{15}$ Thus, the present

${ }^{13}$ The existence of response order effects, as found by Krosnick and Alwin (1987), do not affect our present results, since we use only those years or subsamples of the General Social Survey in which the order of presentation of the list of child qualities was exactly the same as that presented to Kohn's 1964 respondents.

${ }_{14}^{14}$ Duncan (1985) and Alwin and Jackson (1982b) present some evidence of conceptual and empirical convergence of Kohn's (1969) measure of "self-direction vs. conformity" with other measures of the distinction between autonomy on the one hand and obedience on the other. Still, because of the absence in this measure of qualities specifically linked to the exercise of independent thought and action, I acknowledge a serious limitation of these measures for present purposes.

${ }^{15}$ By contrast, Alwin $(1984,1986)$ uses Lenski's (1961) concept of moral autonomy vs. moral heteronomy, and a measure of this concept that directly assesses the contrast between parental values for autonomy vs. obedience. 
set of measures may adequately assess the aspect of conformity of interest here, but possibly not the critical aspect of autonomy of interest. The third limitation of the present measures involves the potential problem of differences in question wording. The 1964 Kohn-NORC study asked these questions with respect to a (randomly selected) child of the respondent, whereas the later GSS surveys referred instead to children in general. There is no evidence that the difference in question wording affects the ranked preferences given. One would expect, as Kohn (1976, p. 541) argued, respondents asked the general question will, in fact, respond in terms of the qualities preferred in children the age and sex of their own children. ${ }^{16}$ Given this assumption, I see no reason to expect that question-wording and the age of the children considered will have any appreciable effect on my results. I nonetheless investigate this issue in the GSS data.

\section{Changes in Parental Values Since 1964}

Using these data I examined three related measures of value change at each of these four time-points: (1) the percentage of respondents selecting a given trait as one of the three most important traits for children to have, (2) the percentage of respondents selecting a given trait as the most important trait to have, and (3) the mean rankings given the traits using the 1-5 scale mentioned in footnote 6 above. These figures are given in Table 1 for all items included on Kohn's list of child qualities. They are based on male parents with children aged 3-15 in the 1964 data and comparable parents living in households with children aged 6-17 in the GSS data for 1973-1975, 1976-1978, and 1980-1984, consistent with Kohn's (1976, p. 541) recommendations. There exist no data from women

\footnotetext{
${ }^{16}$ Commenting on Wright and Wright's (1976) comparison of the 1964 data with the 1973 GSS data, Kohn (1976, p. 541) argued that, as a consequence of the differences in the questions involved in the two datasets, different results would be produced as a function of different ages of children considered by respondents. I control for this possibility in the following analysis by more precise sample selection procedures than those used by the Wrights. A similar argument was advanced by a reviewer of an earlier version of this paper (not a reviewer for Social Science Research). The reviewer discounts the secular differences presented below on the grounds that those differences are artifacts of method differences, stating: "the only way (emphasis added) to resolve such a dispute is to repeat one or the other method of inquiry, to see if one finds changes from one survey to another when using the same methods." Of course, such an experiment would be interesting, but for the critical historical period covered by the present set of surveys, such an experiment is impossible. And, in the absence of such experimental results, and in line with the usual canons of scientific inquiry, until such time as when some evidence is brought to bear on it, such a hypothesis for the differences ohserved in these surveys should not be seriously entertained. The burden of proof lies with those, such as Kohn (1976), who argue it makes a difference, and lacking such evidence, we are here unconstrained by such provisional hypotheses.
} 


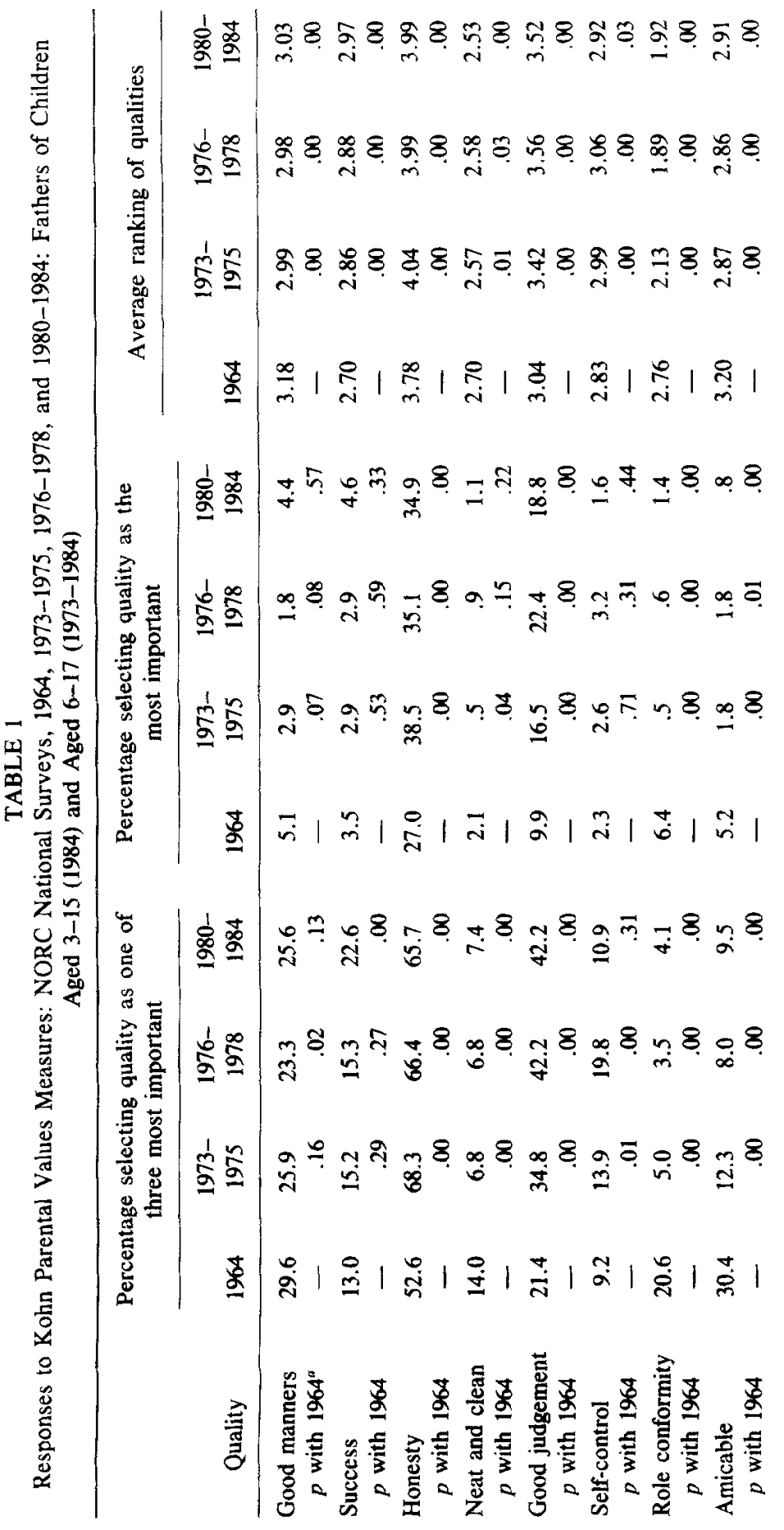




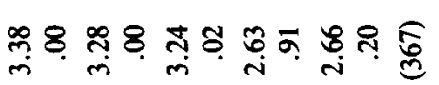

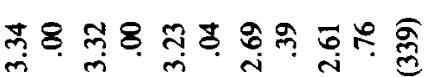

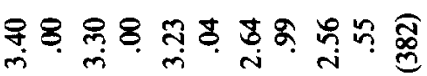

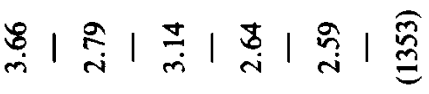

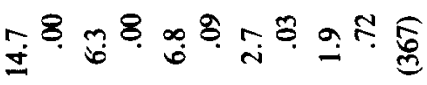

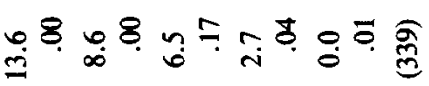

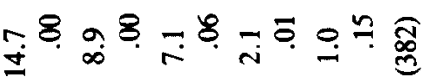

चे|त्र1

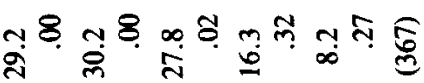

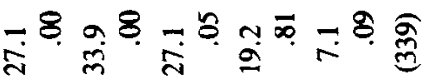

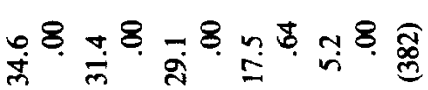

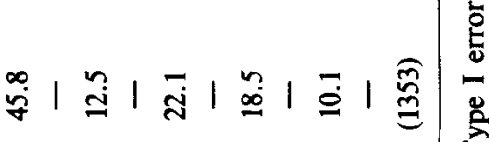

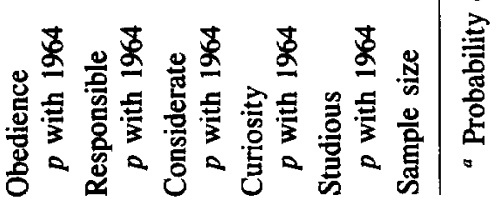


in the 1964 study. ${ }^{17}$ For each post-1964 time period there is given a $p$ value for the test statistic for examining the difference of means between 1964 and the later years.

These results show substantial change in our central indicators of parental values of autonomy and conformity between 1964 and the 1970s and 1980s. For example, the percentage of men selecting the trait "good sense and sound judgement," which is an important indicator of selfdirection, as one of the three most important qualities for children to have, increased from 21.5 in 1964 , to 34.8 in the early $1970 \mathrm{~s}$, and to $42.2 \%$ in the late $1970 \mathrm{~s}$ and early $1980 \mathrm{~s}$. By contrast, the percentage of men selecting "obedience," a critical aspect of Kohn's concept of conformity, declined as one of the three most important qualities from 45.9 in 1964 , to 34.6 in the early $1970 \mathrm{~s}$, and to 27.1 and 29.2 in the late $1970 \mathrm{~s}$ and early $1980 \mathrm{~s}$, respectively.

Other aspects of autonomy and conformity show clear evidence of change in these data as well. ${ }^{18}$ Preferences for the qualities "responsible" and "considerate" both increased over this period, and preferences for "good manners," "neat and clean," and "good student" declined. In this regard, the only quality associated with Kohn's concept of selfdirection vs. conformity that did not change in the expected direction was "interested in how and why things happen" (curiosity), which remained relatively stable between 1964 and 1984 .

These results are in close agreement with those obtained by Wright and Wright (1976, p. 531) from their analysis of "the most important" quality in the 1964 and 1973 GSS data. Further, the figures in Table 1 also provide support for the conclusion that these trends persisted through the decade of the 1970 s and in a few instances into the $1980 \mathrm{~s}$ (see below). And it perhaps deserves comment that these findings do not depend on any single indicator of change in parental values-a similar pattern is revealed by all three measures of change given in Table 1in contrast to the conclusions of Kohn $(1976$, p. 541).

\section{Parental Values and Age of Children}

As noted above, Kohn (1976) argued that the Wright's (1976) presentation of these findings as evidence of social change was suspect, since

${ }^{17}$ I restrict these comparisons to men in order to control for whatever variation there is by gender in these patterns. In addition, it should perhaps be mentioned that in the GSS data it is not possible to determine if the men and women in GSS households are in fact performing "parenting" roles, since the GSS data do not record this information (see NORC, 1988).

${ }^{18}$ In Kohn's analysis, the qualities associated with self-direction are considerate, curious, responsible, self-control, and good sense and sound judgement. The traits associated with conformity are obedience, good manners, being neat and clean, and good student (see Kohn, 1969, p. 58). 
the 1964 and 1973 samples were apparently based on fathers with children of different ages. For several reasons, it is theoretically important to assess the role played by ages of children in responses of parents to questions assessing parental values. If the ages of children condition the types of values held for their behavior by parents, and if the ages of the children of respondents in the 1964 and the GSS surveys differ as a function of survey design, then one may have reason to be suspicious of the conclusion of value change between 1964 and later years. Although the GSS does not permit a precise estimate of the ages of the respondents' children, we can, using somewhat crude partitions of the data, measure the extent to which ages of children affect responses to our principal indicators of parental values.

In the analysis of GSS data presented here, I classify respondents by ages of children using three crude categories, as follows: (1) respondents whose children's ages range between 0 and 5, (2) respondents with children, any of which are aged 6-12, and (3) respondents whose children's ages range between 13 and $17 .{ }^{19}$ This permits the comparison of respondents with (only) young children and those with (only) older children to those in between, i.e., those with any children in the 6-12 age range. In the GSS data the first and third categories each contains approximately one-fourth of the cases, while the second contains about one-half of GSS parents.

Table 2 presents the mean rankings for the child qualities assessed by the Kohn questions by categories of ages of children for both fathers $(n=1480)$ and mothers $(n=2210)$ in the GSS surveys $(1973-1984)$. It is remarkable that for men only two of the traits associated with Kohn's concept of maturity vs. immaturity show any differences across the age categories. ${ }^{20}$ These traits, being a "good student" and "getting along with other children," do seem to be mildly affected by the age categories used here.

Preferences for successful school performance on the part of children are naturally more prevalent among fathers of older children. The trait "getting along with other children," on the other hand, is significantly more often preferred among men with younger children. Both of these patterns make theoretical sense in terms of the developmental goals parents have for children of different ages, however, the differences are very slight, and one can safely conclude that the GSS fathers are re-

${ }^{19}$ Recall that the above analysis, given in Table 1, uses only those fathers with children aged 6-17, as recommended by Kohn (1976, p. 541).

${ }^{20}$ The qualities in Kohn's $(1969$, p. 58$)$ analysis related to maturity/immaturity are responsible, good student, honest, good sense and sound judgement, and the qualities associated with immaturity are (lack of) interest in why and how things happen, obeys parents well, acts like a boy or girl should, and gets along with other children. 
TABLE 2

Mean Importance Rankings for Child Qualities by Age of Children:

GSS Parents 1973-1984

\begin{tabular}{|c|c|c|c|c|c|}
\hline \multirow[b]{2}{*}{ Quality } & \multicolumn{5}{|c|}{ Age of children } \\
\hline & Less than 6 & $6-12$ & $13-17$ & $F$ & $p$ \\
\hline \multicolumn{6}{|c|}{ Fathers, $N=1480$} \\
\hline Good manners & 3.0 & 3.0 & 3.0 & .22 & .80 \\
\hline Success & 2.8 & 2.9 & 2.9 & 1.50 & .22 \\
\hline Honesty & 4.0 & 4.0 & 4.0 & .58 & .57 \\
\hline Neat and clean & 2.5 & 2.6 & 2.6 & .24 & .79 \\
\hline Good judgement & 3.5 & 3.5 & 3.5 & .13 & .88 \\
\hline Self-control & 3.0 & 3.0 & 3.0 & .33 & .72 \\
\hline Role conformity & 2.0 & 2.0 & 2.0 & .20 & .82 \\
\hline Amicable & 3.0 & 2.9 & 2.9 & 6.30 & .00 \\
\hline Obedience & 3.4 & 3.4 & 3.3 & .35 & .71 \\
\hline Responsible & 3.3 & 3.3 & 3.3 & .90 & .41 \\
\hline Considerate & 3.3 & 3.3 & 3.2 & 2.20 & .11 \\
\hline Curiosity & 2.7 & 2.7 & 2.6 & 1.50 & .22 \\
\hline Studious & 2.5 & 2.6 & 2.7 & 6.40 & .00 \\
\hline$n$ & 392 & 756 & 332 & & \\
\hline \multicolumn{6}{|c|}{ Mothers, $N=2210$} \\
\hline Good manners & 3.1 & 3.0 & 2.9 & 7.30 & .00 \\
\hline Success & 2.8 & 2.8 & 2.9 & 3.30 & .04 \\
\hline Honesty & 4.0 & 4.1 & 4.1 & 2.00 & .13 \\
\hline Neat and clean & 2.5 & 2.5 & 2.4 & .41 & .67 \\
\hline Good judgement & 3.5 & 3.5 & 3.5 & .16 & .85 \\
\hline Self-control & 3.1 & 3.1 & 3.1 & .28 & .76 \\
\hline Role conformity & 1.8 & 1.8 & 1.9 & 3.50 & .03 \\
\hline Amicable & 3.0 & 3.0 & 2.9 & 8.60 & .00 \\
\hline Obedience & 3.4 & 3.4 & 3.4 & .33 & .72 \\
\hline Responsible & 3.3 & 3.4 & 3.5 & 5.50 & .00 \\
\hline Considerate & 3.4 & 3.3 & 3.3 & 1.30 & .26 \\
\hline Curiosity & 2.7 & 2.6 & 2.6 & 4.30 & .01 \\
\hline Studious & 2.4 & 2.6 & 2.6 & 10.80 & .00 \\
\hline$n$ & 543 & 1219 & 448 & & \\
\hline
\end{tabular}

sponding to these questions in a more general way than simply in terms of the ages of their children. In other words, among fathers in the GSS sample, there is only weak support for Kohn's (1976, p. 541) assertion that "parents of somewhat older children, asked what characteristics they value for children of unspecified age, tend to choose those that are appropriate for older children." In any case, among the data analyzed by Wright and Wright (1976) and Kohn (1976), the two traits that are so 
affected by children's ages do not bear any important relationship to the principle concepts of autonomy and conformity of concern here. ${ }^{21}$

There are, by contrast, several significant differences by age among mothers along these same lines, however, it is important to note that since the GSS mother sample is somewhat larger $(n=2210)$ it is easier for a given difference to achieve statistical significance in this sample. This means that we must either exact a more extreme statistical standard in evaluating the differences among females or compare only the absolute mean levels between men and women. In any case, the data in Table 2 reveal significant differences among mothers with children of different ages for several traits. Mothers with older children prefer more "responsibility," more "role conformity," more "success" orientation, and less "curiosity," less "good manners," and less "amicability" than those with younger children. And, like fathers, mothers with older children are more likely to select the trait "good student." For only two of these traits, however, are the mother patterns actually different from those of fathers, reflecting a substantively interesting interaction between gender of parent and responsiveness to general age differences of children. The traits "responsible" and "good manners" are affected by ages of children only among mothers. The remaining statistically significant differences do not seem to differ from the patterns for men, and it may be that their greater level of statistical significance results mainly from the larger sample size upon which they are based, and they therefore should not be considered substantively interesting in this context. Still, the differences which are both statistically significant and substantively meaningful, namely the patterns by age of children among mothers for the traits "responsible" and "good manners," are reflective of differences in desired preferences for self-direction and conformity-mothers of older children preferring greater self-direction and mothers of younger children greater conformity. One might also argue that such differences primarily reflect differences in maturity versus immaturity rather than a difference in self-direction versus conformity (Kohn, 1976, p. 541), however, only the quality "responsibility" is apparently linked to both of these more general concepts (or factors) (see Kohn, 1969, p. 58). And the quality "good manners" is the only one of these traits linked to self-direction vs. conformity (Kohn, 1969, p. 58).

Given this set of results, there appears to be no support for Kohn's claim that the changes observed by Wright and Wright (1976) are to be understood solely as a "methodological artifact." Obviously, since (as Table 2 shows) the GSS male respondents' answers are generally not

${ }^{21}$ The exception is the quality "good student," which is linked to both the concept of autonomy vs. conformity and the concept of maturity vs. immaturity. 
conditioned by the aggregate age characteristics of their children, one should perhaps not expect there to be an effect of age of children in the GSS data, as Kohn (1976, p. 541) argued. Certainly, when the respondent is asked to explicitly consider the age and sex of one of the respondent's children, there may be a potential effect of "age of children." 22 However, this is clearly not, nor could it be, a large factor in responses to the GSS child qualities questions, since the GSS respondent is not asked to consider this factor. One possible conclusion from this is that GSS (male) respondents, when asked to consider the desirable qualities of children, in general, interpret the questions more or less accurately and provide responses that are not influenced by the traits they may desire more or less in the subset of children they know the best, vis., their own children. Women, on the other hand, seem to be more affected by the developmental correlates of their children's ages.

Since the ages of children bear only a weak relationship, if any, to paternal values, which were the focus of attention in the debate between Wright and Wright (1976) and Kohn (1976) (see Table 1), and because the "age of children" differences are in most instances not substantively important, we might gain some greater stability in our estimates of change in paternal values if we include those parents with young children, so as to increase the sample sizes. These results for fathers with children 0-17 present in the home are given in Table 3. These patterns are not substantially different from those already given in Table 1 for men with children present aged 6-17.

From either set of figures it is clear that substantial support exists for the thesis that parental self-direction/conformity values have changed from the decade of the 1960s into the 1970s and 1980s. And, it is simply incorrect to conclude that child qualities associated with self-direction and conformity did not change between 1964 and 1973, and are instead an "artifact" of the methods used. Indeed, if one considers only the main traits linked to Kohn's self-direction/conformity factor, all tended to change in the direction of greater self-direction and less conformity. ${ }^{23}$

${ }^{22}$ There is a small literature (e.g., Kohn, 1969; Alwin. 1989c), showing that the sex and age of the child affect parental values, when the respondent is asked to consider the age and sex of the child. It remains to be demonstrated that the magnitudes of effects of the child's age on parental rankings of child qualities are sufficiently large to account for the observed differences between the 1964 and later surveys, noted above. Even if one assumes that the age distribution of the child population changed dramatically over this period, the effects of age on preferred child qualities are not large enough to have produced this change.

${ }^{23}$ Recall that Kohn (1976, p. 541) concludes that it is doubtful that parental values have changed, given that the major indicators of child qualities that appear to have changed are those associated with maturity, rather than self-direction/conformity. It can easily be seen that Kohn's conclusion rests on a somewhat narrow definition of what is the critical distinction between autonomy or self-direction, on the one hand, and maturity on the other. 


\section{PARENTAL VALUES SINCE THE 1970S}

The above findings register significant changes in parental values from the mid-1960s into the late $1970 \mathrm{~s}$. The most central of the indicators of the concepts of autonomy and conformity, namely the qualities, "has good sense and sound judgement," "obeys his parents well," "responsible," and "good manners" (among others), show continued patterns of change into the late 1970s. Rarely, however, do there appear to be any substantial changes into the decade of the 1980s. And in a few instances, there even appear to be reversals of trend, although these differences are slight and within the boundaries of sampling error. Table 3 summarizes the results of a set of $t$-tests of differences between years in each of the several measures of trend examined earlier. These results show that, except for the persistent differences of the 1973-1984 GSS surveys from Kohn's 1964 study, there are essentially no statistically significant trends in parental values between the 1970 s and early $1980 \mathrm{~s}$ in these data. ${ }^{24}$ This does not gainsay the possibility that there are not countervailing factors producing change that suppresses its identification in the comparison of simple averages over the marginals. Indeed, any conclusion about whether there has been social change, based on these

Indeed, it is a mistake to think that self-direction/conformity and maturity/immaturity are independent, even though the factors in Kohn's analysis are orthogonal. Traits reflected in self-direction are reflected in maturity in part because self-direction is developmentally linked to age (see Piaget, 1932).

${ }^{24}$ An earlier reviewer, not convinced that the 1964 Kohn survey and the later NORC/GSS surveys contain comparable measures, states: "The opportunity to resolve the issue of whether or not there really have been changes over time in parental values has now been provided by NORC's having repeated the methods of the 1973 General Social Survey in several subsequent surveys. Comparisons to Kohn's 1964 NORC survey now become irrelevant, because any comparisons to that survey are subject to the same methodological indeterminacy as the comparison of the 1964 and 1973 surveys (carried out by Wright and Wright, 1976)." The reviewer continues, "if one found continued change from 1973 to later surveys of the same sort as that found from 1964 to 1973 , then one could argue that the further changes made it proper to use the 1964 survey as an earlier base-line; but the evidence that the change is real and not artifactual would have to come from comparisons of the 1973 NORC GSS to later NORC GSS surveys . . therefore, unless and until someone repeats the Kohn methods on a national sample, the 1973 data are the only justifiable baseline for assessing time trends in parental values." The reader may take this point of view for what merit it has. It is limited in at least three respects: (1) there is no evidence to establish a finding that the Kohn and NORC-GSS question wordings indeed give different results, (2) social change need not be unidirectional in time, change can reverse itself, as in the case of time-trend cycles, and (3) the absence of linear change in the GSS samples does not rule out the possibility of differing types of changes experienced by distinct subgroups of the population (see below). Obviously, in the absence of a study that replicates Kohn's questions on a national sample of parents (fathers) there may be doubt in such reviewer's mind about whether the 1964 to later differences reflect change, but a broader-minded interpretation of these changes may permit greater appreciation of the present set of results. 


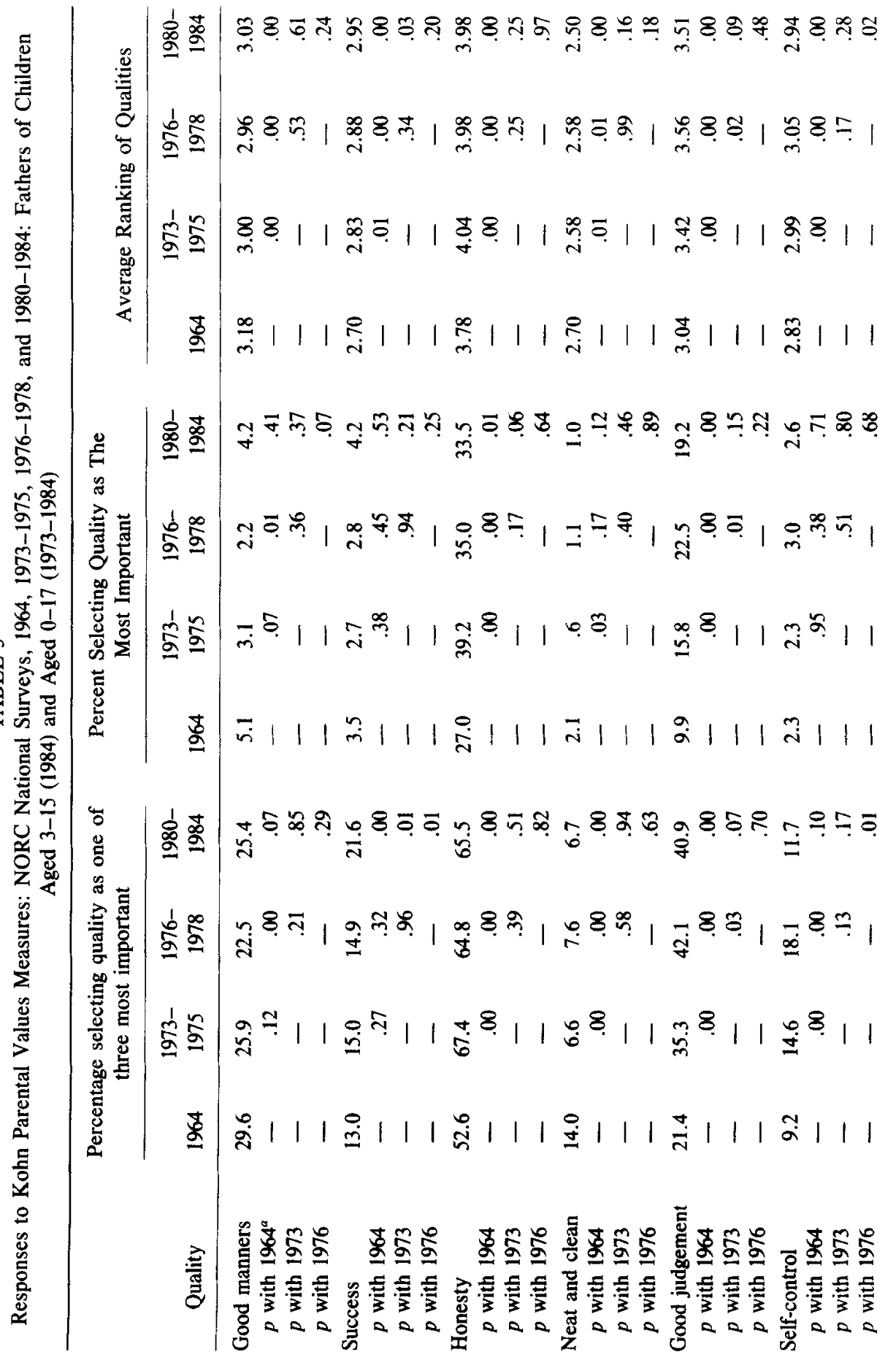




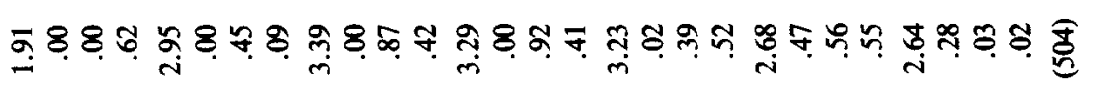

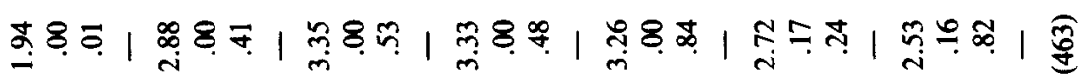

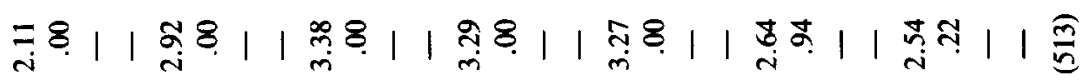

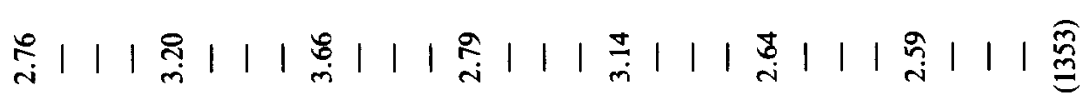
웅ำ 9.

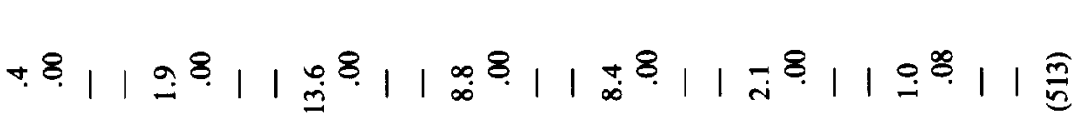

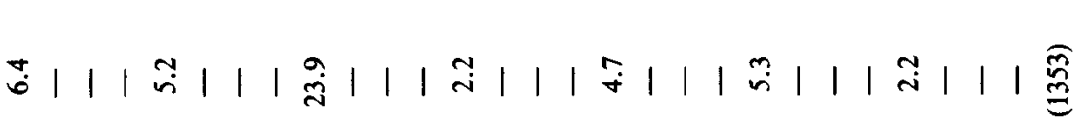
मे 8 ำ

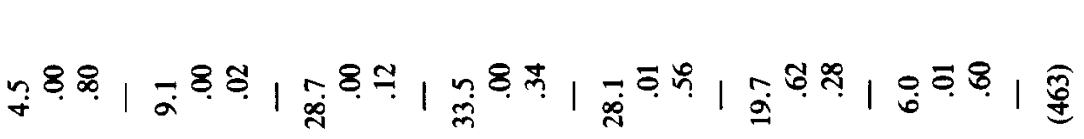
कृ

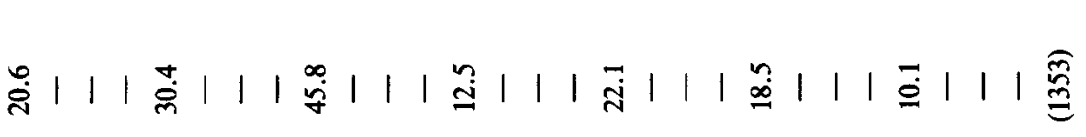

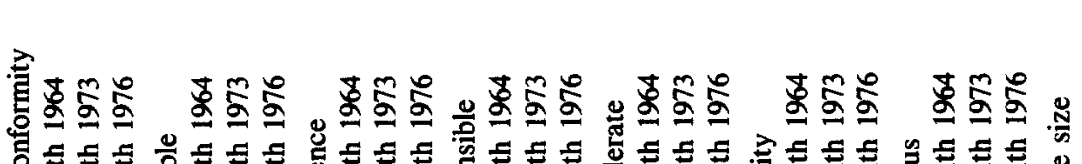

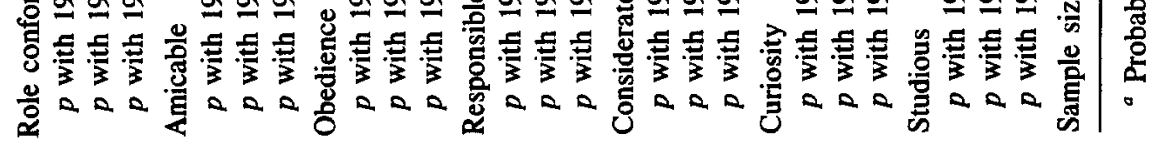


marginals alone, would risk serious error. Thus, in the following investigation I evaluate several potential explanations of trends that bring to bear theoretical considerations, as well as previous research evidence, on the possibility of changes in various subgroups of society. I will examine explanations for both (a) the change between 1964 and later occasions of measurement, and (b) patterns of change since the early 1970s.

\section{EXPLANATIONS OF TRENDS}

Despite significant changes in parental values since 1964, there seems to be a slowing of trends toward greater preferences for autonomy and lesser preferences for conformity in children. But, this does not necessarily signal an end to changes in qualities valued in children. Nor, does it mean that changes are being experienced by all groups in society in the same manner.

There are several possible explanations of these trends, both the dramatic differences between the 1960s and later years and the slowing of the trend into the 1980s. These explanations can be grouped into three categories: (1) those explanations referring to important structural or compositional changes in society, particularly changes in the nature of the distribution of educational and occupational positions (Alwin, 1984; Kohn, 1969); (2) those explanations pointing to cohort or "generational" phenomena, which may implicate intercohort differences in socio-economic and other experiences (see Duncan, 1985; Duncan et al., 1978); (3) those interpretations that emphasize other exogenous cultural changes, affecting all or some of the population, especially changes in the family and other key social institutions (see Alwin, 1986; Inkeles, 1984; Maccoby, 1978; Thornton, 1988).

This set of explanations may not be complete, but it does encompass the major factors that have been used to interpret changes in parental child-rearing orientations. They are obviously not mutually exclusive, and all may in part account for these trends. I here review the following interpretations of the observed changes in parental values: (1) the relation of the birth-cohort composition of the population to trends in parental values, (2) the potential power of changes in educational composition in explaining the value changes between 1964 and 1984, and (3) the extent of exogenous changes in parental values due to historical influences on specific religio-ethnic groups experiencing change in modern society. ${ }^{25}$

\footnotetext{
${ }^{25}$ Because of the fact that women were excluded from Kohn's 1964 study, I have restricted my comparisons to men. An adequate assessment of trends in parental values by gender from 1964 is, thus, not possible. In an analysis of the possibility of gender differences in parental values and differential change by gender in the GSS data since 1973 (data not presented here), I found essentially no major differences. These results reveal a small, systematic gender difference indicating that females have less overall preference
} 


\section{Cohort Replacement vs. Intra-Cohort Change}

One of the most persistent theses in social science is that one's value orientations, as well as the attitudes that spring from them, are potentially influenced by one's membership in a particular "generation" or "cohort" (see Mannheim, 1952; Ryder, 1965). Indeed this issue with respect to cohort differences in political and social attitudes has been the subject of considerable speculation in recent years (Yankelovich, 1984; Wiel, 1987).

If this thesis is true, then parental values should be no exception, and each new generation might be expected to reveal its own unique outlook on children and their upbringing, especially under conditions of social change (e.g., Inkeles, 1983). One popular notion is that parents not only react to the changing social environment, they also react against the ways in which they were raised. Thus, some cohorts may be described as more "individualistic," or more "conformist," than another, and these orientations may in part be responsive to the orientations of the preceding generation (see Duncan, 1985, p. 313). Thus, as proposed by Mannheim (1952), social change may happen in part through a succession of cohorts, each of which experience social life somewhat differently and therefore develop unique orientations.

This issue is very difficult to evaluate using cross-sectional survey data, since in such data, age, period, and cohort effects are difficult, if not impossible, to disentangle (Glenn, 1977; Riley, 1973). However, it is noteworthy that persons born after 1948 were not represented in the 1964 NORC sample, and given the requirement of the measurement of parental values in that study, that persons be raising a child of ages 315 , it is safe to say that persons born roughly after 1943 (those 21 or younger in 1964) were not included in the 1964 study in large numbers. Thus, it is possible to ask whether the differences observed between the 1964 study and the later GSS database might be due to cohort factors, since a large portion of GSS respondents since 1972 were not represented in the 1964 NORC study. I return to this issue in the multivariate analysis presented below.

\section{Social Change and Educational Expansion}

Another possible interpretation of the changes since 1964 is based on some of the ideas of both Weberian and Marxian interpretations of social change (see Bowles and Gintis, 1976; Collins, 1979). Both theories argue

for conformity and greater preference for autonomy than men, but the few significant differences were very small and due largely to the size of the sample $(n=3,690)$. No significant interaction was found in time-trends between men and women. On the basis of this analysis, I concluded that the differences were small enough to justify pooling the data from men and women in the following analyses. 
that structural change has brought about a tremendous expansion of the amount of schooling attained by members of modern American society. Thus, for example, in the late 1800 s little more than $2 \%$ of the American population between 14 and 17 years of age were enrolled in high school, whereas in 1940 some $62 \%$ were so enrolled, and in 1970 the figure was nearly $93 \%$. The percentage of college students of the population 18 to 21 years old went from $2 \%$ in 1870 to nearly $16 \%$ in 1940 , and to over $52 \%$ in 1970 . And in terms of schooling outcomes, some $2 \%$ of the population 21 years or older had obtained a B.A. or first professional degree at the turn of and into the 20th century, 7\% had obtained such a degree in 1940, whereas $21 \%$ had such credentials by 1970 (see Collins, 1979, Table 1.1, p. 4).

Given that education seems to be an important institutional influence on variation in traits of autonomy and conformity (Bowles and Gintis, 1976; Bronfenbrenner, 1977; Miller et al., 1985, 1986), it may be held accountable for changes observed in survey measures of parental values over part or all of this century (e.g., Alwin, 1984; 1988; Kohn, 1969). Of course, the most dramatic changes in the expansion of education occurred since the 1930s, and in more recent times there has been a gradual slowing of the expansion of education witnessed earlier in the century, consistent with the slowing of change in parental desires for autonomy and conformity. The average number of years of schooling in the 1964 data is 11.85; in the 1973-1975 data it is 12.26; in 1976-1978 it was 12.79, and in 1980-1984, 12.78 years. The growth and subsequent leveling off of amounts of schooling may suggest its potential role in explaining trends in preferences for child qualities among the parenting population.

There are several possible interpretations of the role of schooling in parental values, which might be linked to these changes. It is, of course, a commonplace observation that school attendance increases persons' abilities to think for themselves and function independently of others. Kohn, for example, has argued that the greater exposure of individuals to the educational system increases their intellectual flexibility and that this in turn affects parental autonomy and conformity values (1977, p. xiii; 1981, p. 277). Due to the role of the modern school system in allocating persons to jobs, and given the inherent nature of schooling experiences, one would expect there to be other, noncognitive ways in which further schooling might affect parental values and their change (Miller et al., 1985, 1986).

These changes might also operate indirectly through occupational experiences and conditions of work, since as Kohn has repeatedly argued (Kohn, 1963, 1969, 1977, 1981; Kohn et al., 1983), the effects of schooling on parental values are partially mediated by their indirect effects via work experiences. Since education essentially serves as a screening de- 
vice for access to jobs that allow freedom from supervision and opportunities for the exercise of control over the environment, it has a determinative influence on the nature of work. And, to the extent that occupational experiences have an independent influence on parental preferences for the qualities of children, for which Kohn (1969) finds some evidence, then measures of occupational experiences will help transmit the effects of education (cf. Alwin, 1989b). ${ }^{26}$

Finally, schooling also serves to expose persons to a variety of modern values (see Inkeles and Smith, 1974), and especially in the case of childrearing orientations, one would expect that modern higher education would promulgate certain views regarding children and their socialization. Specifically, exposure through schooling to modern psychological theories of child development, which emphasize the movement of the child along a developmental continuum ranging from obedience to autonomy, also presumably explains some of the important effects of education on parental values.

Tables A1-A4, given in the Appendix, present mean levels of importance rankings associated with the amount of schooling received by respondents in the several surveys. These results suggest that the changes in parental values registered above for the total samples are occurring within levels of education as well. There are substantial observed changes between 1964 and the later surveys, but relatively little change into the 1980s. This suggests that, at least in these data, educational differences over time do not appear to explain all of the patterns of change observed above. This, despite some past evidence that changes in parental values are linked to changes in the educational level of the population (Alwin, 1984, 1988).

Still, educational differences over time explain some of the change, albeit perhaps a small portion thereof. Using the 1964-1984 data described above, schooling alone explains (data not presented here) some $21 \%$ of the changes since 1964 in "good manners," $27 \%$ of the changes since 1964 in "neat and clean," $34 \%$ of the changes in "considerate," $9 \%$ of the changes in "obeys parents well," $6 \%$ of the change in "responsible," and $4 \%$ of the change in "good sense and sound judgement." Variance explained in time trends in the remaining traits by intertemporal differences in amounts of schooling in the population was nearly zero.

20 It is not possible to explore these possibilities using the data assembled here, although to do so would provide several revelations regarding the role of occupational influences on parental values. The GSS database has some measures of occupational complexity and job authority, but these factors cannot be implicated in accounting for trends in parental values, since they have not changed in any essential way. Moreover, the GSS measures represent a crude assessment of occupational complexity, since they are based on averages over jobs within the same occupation. 


\section{Religion and Social Change}

One of the findings from Alwin's $(1984,1986)$ research in the Detroit metropolitan area was that from 1958 to 1983 Detroit area Catholics exceeded all other groups in their extent of change in parental socialization values. These changes were given as evidence of the changing role of religio-ethnic factors in shaping orientations to children and relationships in the family. Alwin's (1986) research showed a substantial convergence between white Protestants and Catholics, due mainly to the changes among Catholics, which were interpreted in terms of changes in the orientation of the American Catholic Church toward greater acceptance of autonomy in many areas of individual decision-making, the declining strength of influence of the Church over its members, and the weakening of ethnic subcultural influences among 2nd and 3rd generation Catholics of European origin (see also Greeley, 1977; Alba, 1976, 1981). And given the historical effects on American Catholics of the 2nd Vatican Council (1962-1964), and given that a central dimension on which these influences occurred concerns the extent of individual autonomy versus institutional obedience, one would expect to find substantial changes among Catholics in birth cohorts influenced by these historical events.

This hypothesis is particularly salient in the present context, given Kohn's (1969) and Schooler's (1976) observation of a Catholic-Protestant difference in their concept of self-direction vs. conformity in the 1964 NORC data used here, and given Alwin's (1986) finding of few, if any, differences in the child-rearing orientations of white Protestants and Catholics in the GSS-NORC data obtained for 1973 through 1984. Religious change might potentially account for some of the present results. However, in the present analysis I take birth cohort into account in the examination of religious trends (see multivariate analysis below).

In Tables A5-A8, given in the Appendix, I present mean levels of the Kohn child qualities by religio-ethnic categories for 1964, 1973-1975, 1976-1978, and 1980-1984. Average rankings are given separately for: (a) Catholics, (b) white nonfundamentalist Protestants, (c) white fundamentalist Protestants, (d) black Protestants, (e) Jewish, and (f) no religious preference. ${ }^{27}$ This table also presents the proportion of total variance that lies between religio-ethnic categories, the associated $F$ ratio, and the probability of Type I error for the null hypothesis that there are no differences among religio-ethnic group means.

These results demonstrate some differences between Catholics and white Protestants in 1964, but only trivial differences between these groups in the 1970s and 1980s. In 1964 Catholics were higher than white

\footnotetext{
${ }^{27}$ Respondents are classified according to "religious background" rather than current religious preference, although for the vast majority these are the same. Respondents with "other" religious preference are excluded.
} 
nonfundamentalist Protestants in their preferences for the three main qualities associated with conformity, obedience, being neat and clean, and having good manners, but somewhat similar to fundamentalist white Protestants. By the 1970s, however, these differences seem to have been eroded, in that there are few noticeable differences between these three groups in the 1973-1975, 1976-1978, and 1980-1984 GSS data. Contrary to expectations, based on Kohn's (1969) and Schooler's (1976) work, there were few differences between Catholics and white Protestants in 1964 in their preferences for qualities linked to autonomy.

Despite the significant erosion of Catholic-white Protestant differences over this period, major differences among religio-ethnic categories in the post-1960s data still remain. The distinctive groups in the more recent period are black Protestants and persons of Jewish origins, the former showing somewhat greater than average preferences for qualities linked to conformity and the latter group showing substantially less overall preference for such qualities. Thus, while there are some significant religio-ethnic differences, there are essentially none that form along the lines of what was observed between Catholics and white Protestants in the 1964 data (see also Alwin, 1984, 1986).

Thus, some of the social changes witnessed in the foregoing analysis of these data may be attributed to changes in values experienced by persons identifying themselves as having Catholic origins. However, as noted earlier, these changes may not have been uniformly experienced by all birth cohorts. The verification of these hypotheses requires their further examination within a multivariate context, to which I now turn.

\section{MULTIVARIATE ANALYSIS OF CHANGES IN PARENTAL VALUES}

In order to evaluate these several hypotheses, I analyze the 1964-1984 data for parental values by birth cohort, religious category, and time of observation. Because of the large amount of data to analyze, organize, and present, these analyses selectively focus on the most salient of our indicators of autonomy and obedience. For these purposes we use scores for the evaluation of "good sense and sound judgment" and "responsible" as representatives of the autonomy concept, and scores for "obedience" and "good manners" as measures of obedience.

Tables 4-7 present the average importance rankings (as above, a high score corresponds to greater assigned importance) of these four measures of autonomy vs. obedience. Means are presented for each of several birth cohorts at each of the four time periods of observation for the total eligible sample and within categories of Catholic, Protestant, and white Protestant religious groups. ${ }^{28}$ Average scores are arrayed for respondents

${ }^{28}$ The Protestant group is limited to whites owing to the facts that black and white Protestants are consistently found to be distinct in their parental values (see Alwin, 1984, 1986). 
TABLE 4

Mean Rankings Adjusted for Educational Differences of Selected Child Qualities by Birth Cohort, Time of Survey, and Religio-Ethnic Catcgory: Total Parents with Children $0-17$

\begin{tabular}{|c|c|c|c|c|c|c|c|c|}
\hline Birth cohort & $60-69$ & $50-59$ & $40-49$ & $30-39$ & $20-29$ & $10-19$ & $<1910$ & \\
\hline \multirow[b]{2}{*}{ Characteristic } & \multicolumn{8}{|c|}{ Age in 1964 (1964 survey) } \\
\hline & & & $16-24$ & $25-34$ & $35-44$ & $45-54$ & $55-64$ & Total \\
\hline Obedience & & & 3.68 & 3.79 & 3.62 & 3.52 & 3.50 & 3.64 \\
\hline Good manners & & & 3.26 & 3.20 & 3.16 & 3.08 & 3.23 & 3.16 \\
\hline \multirow{4}{*}{$\begin{array}{l}\text { Good judgement } \\
\text { Responsible } \\
\text { Sample size }\end{array}$} & & & 2.95 & 2.95 & 3.05 & 3.08 & 3.23 & 3.05 \\
\hline & & & 2.62 & 2.61 & 2.87 & 2.95 & 2.93 & 2.80 \\
\hline & & & $(27)$ & $(412)$ & (579) & $(278)$ & $(57)$ & (1353) \\
\hline & \multicolumn{8}{|c|}{ Age in 1974 (1973-1975 surveys) } \\
\hline Characteristic & & $16-24$ & $25-34$ & $35-44$ & $45-54$ & $55-64$ & $65-74$ & Total \\
\hline Obedience & & 3.32 & 3.34 & 3.30 & 3.29 & 3.58 & 3.12 & 3.32 \\
\hline Good manners & & 3.09 & 2.96 & 2.98 & 2.89 & 2.74 & 3.02 & 2.96 \\
\hline \multirow{4}{*}{$\begin{array}{l}\text { Good judgement } \\
\text { Responsible } \\
\text { Sample size }\end{array}$} & & 3.40 & 3.55 & 3.47 & 3.52 & 3.55 & 3.46 & 3.50 \\
\hline & & 3.21 & 3.36 & 3.37 & 3.53 & 3.23 & 3.21 & 3.36 \\
\hline & & $(165)$ & (411) & (392) & (197) & $(60)$ & (24) & (1249) \\
\hline & \multicolumn{8}{|c|}{ Age in 1978 (1976-1978 surveys) } \\
\hline Characteristic & & $20-28$ & $29-38$ & $39-48$ & $49-58$ & $59-68$ & $69-78$ & Total \\
\hline Obedience & & 3.40 & 3.42 & 3.37 & 3.29 & 3.33 & 3.44 & 3.38 \\
\hline Good manners & & 3.17 & 2.99 & 2.88 & 2.91 & 2.85 & 3.04 & 2.96 \\
\hline Good judgement & & 3.37 & 3.47 & 3.55 & 3.57 & 3.73 & 3.54 & 3.51 \\
\hline Responsible & & 3.28 & 3.35 & 3.42 & 3.36 & 3.56 & 3.15 & 3.37 \\
\hline \multirow[t]{2}{*}{ Sample size } & & $(100)$ & $(457)$ & $(353)$ & (166) & $(50)$ & (19) & (1145) \\
\hline & \multicolumn{8}{|c|}{ Age in 1984 (1980-1984 surveys) } \\
\hline Characteristic & $17-24$ & $25-34$ & $35-44$ & $45-54$ & $55-64$ & $65-74$ & & Total \\
\hline Obedience & 3.59 & 3.45 & 3.39 & 3.30 & 3.54 & 3.46 & & 3.42 \\
\hline Good manners & 3.25 & 3.12 & 2.97 & 3.04 & 3.08 & 2.96 & & 3.06 \\
\hline Good judgement & 3.23 & 3.43 & 3.49 & 3.53 & 3.49 & 3.34 & & 3.45 \\
\hline Responsible & 3.25 & 3.30 & 3.39 & 3.43 & 3.29 & 3.20 & & 3.34 \\
\hline Sample size & (74) & $(502)$ & (424) & (165) & (51) & (27) & & (1243) \\
\hline Characteristic & \multicolumn{8}{|c|}{ Mean for birth cohort } \\
\hline Obedience & 3.59 & 3.42 & 3.39 & 3.47 & 3.49 & 3.51 & 3.39 & \\
\hline Good manners & 3.25 & 3.12 & 2.98 & 3.03 & 3.04 & 3.00 & 3.14 & \\
\hline Good judgement & 3.23 & 3.42 & 3.49 & 3.34 & 3.27 & 3.31 & 3.28 & \\
\hline Responsible & 3.25 & 3.28 & 3.35 & 3.16 & 3.10 & 3.11 & 3.04 & \\
\hline Sample size & (74) & $(725)$ & (1311) & (1317) & (1016) & (413) & (99) & (4955) \\
\hline
\end{tabular}


TABLE 5

Mean Rankings Adjusted for Educational Differences of Selected Child Qualities by Birth Cohort and Time of Survey: Catholic Parents with Children 0-17

\begin{tabular}{|c|c|c|c|c|c|c|c|c|}
\hline \multirow[b]{3}{*}{ Characteristic } & $60-69$ & $50-59$ & $40-49$ & $30-39$ & $20-29$ & $10-19$ & $<1910$ & \\
\hline & \multicolumn{8}{|c|}{ Age in 1964 (1964 survey) } \\
\hline & & & $16-24$ & $25-34$ & $35-44$ & $45-54$ & $55-64$ & Total \\
\hline Obedience & & & 3.62 & 3.80 & 3.78 & 3.63 & 3.52 & 3.74 \\
\hline Good manners & & & 3.59 & 3.27 & 3.22 & 3.20 & 3.14 & 3.23 \\
\hline Good judgement & & & 3.39 & 2.92 & 2.92 & 3.24 & 3.25 & 3.01 \\
\hline Responsible & & & 3.38 & 2.55 & 2.79 & 2.89 & 2.58 & 2.74 \\
\hline \multirow[t]{2}{*}{ Sample size } & & & (3) & (120) & (166) & (97) & (12) & (398) \\
\hline & \multicolumn{8}{|c|}{ Age in 1974 (1973-1975 surveys) } \\
\hline Characteristic & & $16-24$ & $25-34$ & $35-44$ & $45-54$ & $55-64$ & $65-74$ & Total \\
\hline Obedience & & 3.14 & 3.37 & 3.27 & 3.24 & 3.74 & 3.10 & 3.31 \\
\hline Good manners & & 3.00 & 2.98 & 3.01 & 2.85 & 2.79 & 2.24 & 2.95 \\
\hline \multirow{4}{*}{$\begin{array}{l}\text { Good judgement } \\
\text { Responsible } \\
\text { Sample size }\end{array}$} & & 3.40 & 3.49 & 3.62 & 3.38 & 3.52 & 3.32 & 3.50 \\
\hline & & 3.46 & 3.38 & 3.44 & 3.49 & 3.70 & 2.91 & 3.43 \\
\hline & & (32) & (116) & (111) & (62) & $(16)$ & (5) & (342) \\
\hline & \multicolumn{8}{|c|}{ Age in 1978 (1976-1978 surveys) } \\
\hline Characteristic & & $20-28$ & $29-38$ & $39-48$ & $49-58$ & $59-68$ & $69-78$ & Total \\
\hline Obedience & & 3.31 & 3.28 & 3.27 & 3.28 & 3.41 & 2.95 & 3.28 \\
\hline Good manners & & 3.17 & 2.98 & 2.80 & 2.82 & 2.68 & 3.92 & 2.90 \\
\hline \multirow{4}{*}{$\begin{array}{l}\text { Good judgement } \\
\text { Responsible } \\
\text { Sample size }\end{array}$} & & 3.45 & 3.53 & 3.52 & 3.47 & 3.88 & 3.06 & 3.52 \\
\hline & & 3.14 & 3.35 & 3.44 & 3.50 & 3.74 & 4.06 & 3.41 \\
\hline & & (29) & (141) & (119) & (56) & (14) & (2) & (361) \\
\hline & \multicolumn{8}{|c|}{ Age in 1984 (1980-1984 surveys) } \\
\hline Characteristic & $17-24$ & $25-34$ & $35-44$ & $45-54$ & $55-64$ & $65-74$ & & Total \\
\hline Obedience & 3.20 & 3.34 & 3.28 & 3.10 & 3.66 & 3.25 & & 3.29 \\
\hline Good manners & 3.02 & 3.15 & 2.98 & 2.88 & 2.85 & 3.02 & & 3.03 \\
\hline Good judgement & 3.04 & 3.32 & 3.56 & 3.71 & 3.28 & 3.61 & & 3.46 \\
\hline Responsible & 3.19 & 3.28 & 3.59 & 3.50 & 3.61 & 3.43 & & 3.41 \\
\hline Sample size & (13) & $(152)$ & $(131)$ & (55) & (15) & (6) & & (372) \\
\hline Characteristic & \multicolumn{8}{|c|}{ Mean for birth cohort } \\
\hline Obedience & 3.20 & 3.31 & 3.31 & 3.40 & 3.57 & 3.60 & 3.35 & \\
\hline Good manners & 3.02 & 3.13 & 2.99 & 3.01 & 3.05 & 3.09 & 2.99 & \\
\hline Good judgement & 3.04 & 3.35 & 3.53 & 3.39 & 3.14 & 3.36 & 3.25 & \\
\hline Responsible & 3.09 & 3.29 & 3.41 & 3.18 & 3.11 & 3.10 & 2.82 & \\
\hline Sample size & (13) & (213) & (391) & $(405)$ & (299) & (133) & (19) & (1473) \\
\hline
\end{tabular}


TABLE 6

Mean Rankings Adjusted for Educational Differences of Selected Child Qualities by Birth Cohort and Time of Survey: Protestant Parents with Children 0-17

\begin{tabular}{|c|c|c|c|c|c|c|c|c|}
\hline Birth cohort & $60-69$ & $50-59$ & $40-49$ & $30-39$ & $20-29$ & $10-19$ & $<1910$ & \\
\hline \multirow[b]{2}{*}{ Characteristic } & \multicolumn{8}{|c|}{ Age in 1964 (1964 survey) } \\
\hline & & & $16-24$ & $25-34$ & $35-44$ & $45-54$ & $55-64$ & Total \\
\hline Obedience & & & 3.71 & 3.81 & 3.54 & 3.47 & 3.53 & 3.61 \\
\hline Good manners & & & 3.14 & 3.20 & 3.14 & 3.02 & 3.26 & 3.14 \\
\hline \multirow{4}{*}{$\begin{array}{l}\text { Good judgement } \\
\text { Responsible } \\
\text { Sample size }\end{array}$} & & & 2.98 & 2.97 & 3.10 & 3.14 & 3.01 & 3.06 \\
\hline & & & 2.51 & 2.64 & 2.90 & 2.97 & 2.98 & 2.82 \\
\hline & & & $(23)$ & $(276)$ & $(383)$ & (169) & $(42)$ & (893) \\
\hline & \multicolumn{8}{|c|}{ Age in 1974 (1973-1975 surveys) } \\
\hline Characteristic & & $16-24$ & $25-34$ & $35-44$ & $45-54$ & $55-64$ & $65-74$ & Total \\
\hline Obedience & & 3.35 & 3.33 & 3.32 & 3.32 & 3.53 & 3.13 & 3.33 \\
\hline Good manners & & 3.11 & 2.95 & 2.96 & 2.89 & 2.73 & 3.20 & 2.95 \\
\hline Good judgement & & 3.40 & 3.56 & 3.44 & 3.58 & 3.53 & 3.48 & 3.51 \\
\hline Responsible & & 3.11 & 3.36 & 3.32 & 3.44 & 3.32 & 3.28 & 3.33 \\
\hline \multirow[t]{2}{*}{ Sample size } & & $(87)$ & $(267)$ & $(266)$ & $(154)$ & $(44)$ & (20) & (838) \\
\hline & \multicolumn{8}{|c|}{ Age in 1978 (1976-1978 surveys) } \\
\hline Characteristic & & $20-28$ & $29-38$ & $39-48$ & $49-58$ & $59-68$ & $69-78$ & Total \\
\hline Obedience & & 3.36 & 3.48 & 3.42 & 3.35 & 3.48 & 3.49 & 3.44 \\
\hline Good manners & & 3.23 & 3.01 & 2.92 & 2.98 & 2.92 & 2.93 & 2.99 \\
\hline Good judgement & & 3.35 & 3.43 & 3.55 & 3.58 & 3.62 & 3.58 & 3.49 \\
\hline Responsible & & 3.32 & 3.35 & 3.38 & 3.29 & 3.50 & 3.05 & 3.35 \\
\hline \multirow[t]{2}{*}{ Sample size } & & $(64)$ & $(296)$ & $(219)$ & (99) & $(35)$ & (17) & (730) \\
\hline & \multicolumn{8}{|c|}{ Age in 1984 (1980-1984 surveys) } \\
\hline Characteristic & $17-24$ & $25-34$ & $35-44$ & $45-54$ & $55-64$ & $65-74$ & & Total \\
\hline Obedience & 3.72 & 3.53 & 3.43 & 3.42 & 3.51 & 3.53 & & 3.49 \\
\hline Good manners & 3.30 & 3.14 & 2.97 & 3.17 & 3.09 & 2.83 & & 3.09 \\
\hline Good judgement & 3.18 & 3.44 & 3.46 & 3.44 & 3.56 & 3.22 & & 3.43 \\
\hline Responsible & 3.27 & 3.31 & 3.34 & 3.30 & 3.16 & 3.14 & & 3.30 \\
\hline Sample size & (53) & $(323)$ & $(275)$ & $(95)$ & $(35)$ & $(20)$ & & $(801)$ \\
\hline Characteristic & \multicolumn{8}{|c|}{ Mean for birth cohort } \\
\hline Obedience & 3.72 & 3.47 & 3.43 & 3.51 & 3.46 & 3.49 & 3.42 & \\
\hline Good manners & 3.30 & 3.15 & 2.98 & 3.05 & 3.06 & 2.95 & 3.17 & \\
\hline Good judgement & 3.18 & 3.42 & 3.47 & 3.32 & 3.30 & 3.28 & 3.25 & \\
\hline Responsible & 3.27 & 3.27 & 3.33 & 3.11 & 3.09 & 3.11 & 3.07 & \\
\hline Sample size & (53) & $(474)$ & $(861)$ & $(856)$ & $(671)$ & $(268)$ & (79) & (3262) \\
\hline
\end{tabular}


TABLE 7

Mean Rankings Adjusted for Educational Differences of Selected Child Qualities by Birth Cohort and Time of Survey: White Protestant Parents with Children 0-17

\begin{tabular}{|c|c|c|c|c|c|c|c|c|}
\hline Birth cohort & $60-69$ & $50-59$ & $40-49$ & $30-39$ & $20-29$ & $10-19$ & $<1910$ & \\
\hline \multirow[b]{2}{*}{ Characteristic } & \multicolumn{8}{|c|}{ Age in 1964 (1964 survey) } \\
\hline & & & $16-24$ & $25-34$ & $35-44$ & $45-54$ & $55-64$ & Total \\
\hline Obedience & & & 3.71 & 3.81 & 3.54 & 3.47 & 3.53 & 3.61 \\
\hline Good manners & & & 3.14 & 3.20 & 3.14 & 3.02 & 3.26 & 3.14 \\
\hline \multirow{4}{*}{$\begin{array}{l}\text { Good judgement } \\
\text { Responsible } \\
\text { Sample size }\end{array}$} & & & 2.98 & 2.97 & 3.10 & 3.14 & 3.01 & 3.06 \\
\hline & & & 2.51 & 2.64 & 2.90 & 2.97 & 2.98 & 2.82 \\
\hline & & & (23) & (276) & (383) & $(169)$ & $(42)$ & $(893)$ \\
\hline & \multicolumn{8}{|c|}{ Age in 1974 (1973-1975 surveys) } \\
\hline Characteristic & & $16-24$ & $25-34$ & $35-44$ & $45-54$ & $55-64$ & $65-74$ & Total \\
\hline Obedience & & 3.23 & 3.29 & 3.28 & 3.33 & 3.59 & 3.17 & 3.30 \\
\hline Good manners & & 3.06 & 2.84 & 2.90 & 2.85 & 2.56 & 3.09 & 2.87 \\
\hline Good judgement & & 3.38 & 3.58 & 3.51 & 3.57 & 3.39 & 3.29 & 3.52 \\
\hline Responsible & & 3.23 & 3.42 & 3.38 & 3.48 & 3.41 & 3.33 & 3.39 \\
\hline \multirow[t]{2}{*}{ Sample size } & & $(67)$ & (227) & $(227)$ & $(131)$ & $(37)$ & (14) & (703) \\
\hline & \multicolumn{8}{|c|}{ Age in 1978 (1976-1978 surveys) } \\
\hline Characteristic & & $20-28$ & $29-38$ & $39-48$ & $49-58$ & $59-68$ & $69-78$ & Total \\
\hline Obedience & & 3.42 & 3.45 & 3.39 & 3.36 & 3.49 & 3.56 & 3.42 \\
\hline Good manners & & 2.99 & 2.98 & 2.87 & 2.90 & 2.90 & 4.10 & 2.93 \\
\hline Good judgement & & 3.36 & 3.47 & 3.56 & 3.61 & 3.62 & 3.59 & 3.52 \\
\hline Responsible & & 3.45 & 3.40 & 3.46 & 3.35 & 3.57 & 2.98 & 3.42 \\
\hline \multirow[t]{2}{*}{ Sample size } & & $(47)$ & $(265)$ & $(195)$ & $(83)$ & (29) & (11) & $(630)$ \\
\hline & \multicolumn{8}{|c|}{ Age in 1984 (1980-1984 surveys) } \\
\hline Characteristic & $17-24$ & $25-34$ & $35-44$ & $45-54$ & $55-64$ & $65-74$ & & Total \\
\hline Obedience & 3.60 & 3.45 & 3.44 & 3.42 & 3.55 & 3.55 & & 3.46 \\
\hline Good manners & 3.23 & 3.03 & 2.96 & 3.10 & 3.08 & 3.12 & & 3.03 \\
\hline Good judgement & 3.29 & 3.50 & 3.48 & 3.41 & 3.61 & 3.46 & & 3.47 \\
\hline Responsible & 3.30 & 3.36 & 3.36 & 3.36 & 3.27 & 3.01 & & 3.35 \\
\hline Sample size & (41) & $(260)$ & $(247)$ & (79) & $(28)$ & (14) & & $(669)$ \\
\hline Characteristic & \multicolumn{8}{|c|}{ Mean for birth cohort } \\
\hline Obedience & 3.60 & 3.41 & 3.41 & 3.51 & 3.47 & 3.49 & 3.45 & \\
\hline Good manners & 3.23 & 3.03 & 2.94 & 3.02 & 3.05 & 2.95 & 3.20 & \\
\hline Good judgement & 3.29 & 3.46 & 3.49 & 3.32 & 3.29 & 3.25 & 3.17 & \\
\hline Responsible & 3.30 & 3.35 & 3.36 & 3.13 & 3.10 & 3.11 & 3.06 & \\
\hline Sample size & (41) & $(374)$ & $(762)$ & $(777)$ & $(625)$ & (249) & $(67)$ & $(2895)$ \\
\hline
\end{tabular}


born in 1900-1909,1910-1919, 1920-1929, 1930-1939, 1940-1949, 19501959, and 1960-1966. The latter two cohorts are not represented in the 1964 survey and the oldest two cohorts are represented only in small numbers in the GSS surveys. ${ }^{29}$ This table presents means for these four measures adjusted for cohort differences in amounts of schooling.

These results record many of the same patterns noted above with respect to change over time (Tables 1 and 3), that is, within cohort categories there are substantial changes between 1964 and the mid-1970s, with less obvious aggregate change happening into the 1980 s, even after controlling for intercohort differences in amounts of schooling. Most of the groups represented in both the 1964 and 1973-1975 studies show the type of net change described above. However, changes since the $1970 \mathrm{~s}$ are somewhat more subtle and to some extent cohort-dependent, and the nature and extent of change varies by religio-ethnic status. For example, change does seem to be occurring somewhat more strongly into the 1980s among the cohorts born in 1930-1939 and 1940-1949. especially among those persons of Catholic origins. Data are too scarce on the cohorts born prior to the 1930 s to make strong inferences about the nature of their change, although the available data for these cohorts suggest much more continuity than change. ${ }^{30}$

There appears to be some support in the above table for the suggestion that the cohorts born between 1930 and 1950 (both Catholics and Protestants) have been in large part responsible for carrying the trend through the 1970s and into the 1980s. Whereas, the cohorts born earlier and cohorts born later-after 1950-appear to show greater preferences for obedience in children, but only marginally less preference for autonomy. While a cohort-type interpretation here is tempting, especially in the context of considerable speculation regarding the "conservatism" of younger cohorts (e.g., Yankelovich, 1984), such conclusions must take into account the limitations of the available longitudinal assessments for

${ }^{29}$ Recall that for the 1980-1984 time period, three GSS surveys are included from 1980 , 1983, and 1984, and for the 1973-1975 and 1976-1978 periods two GSS surveys are used. I should also point out, as I observed above, that there is some censoring of observations in these data, since some combinations of age and cohort cannot be observed. In the 19501969 cohort category, for example, no ages above 34 are represented, since the observation of this cohort category in the older ages can only be possible in future surveys. Similarly, the pre-1910 cohort is not observed at ages less than 55, since the first available survey occurred in years subsequent to their younger ages. And, even in the two middle cohort categories, some censoring occurs either at the top or the bottom of the age distribution. Despite these limitations of data, each age and cohort category is observed at least twice (see Table 4).

${ }^{30}$ It should also be noted that the GSS survey excludes members of the adult population attending college at the time of the survey and these differences need to be assessed controlling for level of schooling. It is for this reason, among others, that I have adjusted the means in Tables 4-7 for cohort differences in amounts of schooling. 


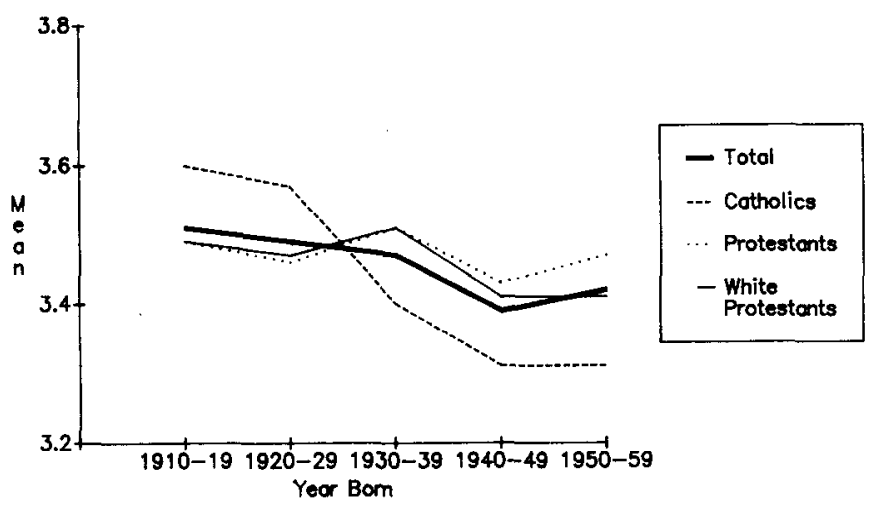

FIG. 1. Mean rankings of "Obeys Parents Well," adjusted for differences in amounts of schooling.

these cohorts, as well as possible religio-ethnic differences in cohort experiences.

It is noteworthy in this context that the primary indicator of parental values showing these patterns is one which is specifically linked to the set of issues raised, and to some extent resolved, by the 2nd Vatican Council-namely the general issue of "obedience," as well as the more specific issue of "obedience to parents." What seems to be suggested by the results in this table is that intercohort differences are linked specifically to this indicator in a way that varies significantly by religioethnic status. Indeed, if one examines the cohort differences in one of our most central indicators, preferences for "obeys parents well," one finds a difference in the intercohort patterns for Catholics and Protestants, as expected. These results are shown graphically in Fig. 1. Here there is relatively clear evidence that the youngest cohorts of Catholics have less preference for obedience than is true of members of cohorts born earlier-those born since the Great Depression show significant declines in preferences for this quality. The results for Protestants show a similar, but less extreme, pattern. The youngest cohorts of Protestants prefer "obedience" to a much greater extent than young Catholics, whereas Protestants from earlier birth cohorts show less overall preference for this quality relative to comparable cohorts of Catholics. ${ }^{31}$ There seems to be a rather clear three-way interaction in these data involving this indicator of preferences for obedience. Similar patterns do not seem to occur for our central measures of parental preferences for autonomy. One could argue, however, that aspects of obedience and

${ }^{31}$ Because of the relatively sparse number of cases for persons in these religio-ethnic categories born before 1910 and after 1960, I have excluded them from the results presented in Fig. 1. These data, however, are given in the relevant tables. 
autonomy need not change in tandem over time, especially if the content of child qualities is irrelevant to the historical effects operating on younger cohorts of parents. One could argue further that the implications of the 2nd Vatican Council were far less for having "good sense and sound judgement," and being "responsible" and "considerate." Rather, the effects of these trends seem to have been more strongly registered in our central indicator of obedience or conformity, and not on the other indicators of this dimension in the Kohn measure. Clearly, some developmental qualities of children may over the long run transcend social and cultural change, while others may be particularly sensitive to social change at one time or another. These results conform in part in this regard to other studies demonstrating change in parental values.

There is one possible challenge to the present interpretations, having to do with "aging" or "life cycle" interpretations of the results in Tables 4-7. Theoretically, both historical changes and aging may produce greater levels of preference for obedience and lesser valuation of autonomy among the older cohorts. However, at least for the indicator of "obeys parents well," there is no support for the idea that historical change is uniform in all groups. If the effects of aging are similarly monotonic in all groups, differences between religio-ethnic categories would suggest differing types of cohort effects for those groups. In other words, such "life cycle" interpretations cannot ignore the possible differences between Catholics and Protestants. The above observations regarding the youngest cohorts of Protestants suggest that a "generational" difference has produced a somewhat more traditional or conservative group of young adults in the 1980s (see Table 6), a difference that produces a countervailing effect of cohort on such linear historical and aging effects. The "generational" effect for Catholics (see Table 5) seems to be in the reverse direction, suggesting that the youngest cohorts of Catholics are continuing to carry forward the trend toward preferences for obedience in children.

Of course, the present comparisons are admittedly relatively crude, and the patterns in Tables 4-7 may actually be masking a larger, more complicated, process that includes effects of time, cohort, and aging over a much longer time period. Moreover, these clear interactions of cohort and religio-ethnic status do not occur with respect to all indicators. Further examination of these issues in future surveys is necessary in order to ascertain the extent to which life cycle vs. cohort factors contribute to variation in parental values. ${ }^{32}$ In any event, despite its limi-

\footnotetext{
${ }^{32}$ A more adequate analysis of cohort effects would not only need to deal with the separation of cohort and period effects, it would have to simultaneously deal with the possible confounding effects of life cycle or aging on parental values. Furthermore, the mathematical identity that cohort $=$ year - age precludes a simple solution to the identification problem (see K. O. Mason et al., 1973; Glenn, 1976, 1977; W. M. Mason et
} 
tations, this multivariate analysis has provided some evidence for the possibility of both period and cohort factors in generating changes in parental values during the period covered by the available national survey record. Period effects associated with the continuing spread of education, and presumably occupational complexity, as argued by Kohn (1969, pp. 193-194), explain a small part of the trend. And, as we pointed out above, the apparent gradual slowing down of the aggregate level of schooling into the 1980 s may be in part responsible for the slowing of social change in parental values. Further, however, there is also some indication of some unique effects for certain birth cohorts, especially those born after the Great Depression (1930-1939 and 1940-1949), and among these cohorts the influences of historical factors on parents of Catholic origins seems to be demonstrated in the previous analysis.

\section{DISCUSSION AND CONCLUSIONS}

I began this paper by noting that over the past several centuries the relationships within the nuclear family in Western societies, particularly those between parents and their children, had changed rather dramatically. With persistent increases in economic development and all of the social changes attendant to it, including declines in fertility and infant mortality (see Stone, 1977), greater affection was shown toward children and considerable attention was paid to their development. Rather than being left to their own devices, children increasingly came under adult control, and parental resources were to a greater extent devoted to their development. Gradually parents came to see children as valuable resources to cherish and cultivate, and over time various philosophies and psychologies have flourished regarding how best to achieve developmental outcomes in children (see Stone, 1977; Schlumbohm, 1980; LeVine and White, 1986).

While many of these long-term changes in parent-child relationships are attributable to economic development and demographic change (see Thornton and Fricke, 1987; Thornton and Freedman, 1983), many can also be seen as rooted in other structural and cultural changes. This conclusion is compatible with the thesis recently developed by Zelizer (1985), who argues that the "economically useful" child of 19th-century industrialized society was eventually replaced by the "economically worthless, but emotionally priceless" child of the 20th. Using a variety

al., 1976; Rodgers, 1982; Smith et al., 1982; Mason and Fienberg, 1985; Hout and Greeley, 1987). Only by making some assumptions regarding the equivalence of certain age, period, or cohort effects is a solution possible. At this stage in my examination of these issues, given the available data resources and their complexity, my preference is to rely on these more descriptive measures, leaving a statistical analysis of age, period, and cohort effects to future research. 
of historical public documents (child labor legislation, life insurance for children, compensation for the death of children, and patterns of adoption and foster care), she observes the gradual prevalence of the view of a nonlaboring child, whose moral value far outweighs any associated economic value, over the view of the child engaged in labor, for which an economic value existed and in terms of which their value was assessed. The emergence of this "sentimentalized" conception of children, wherein their economic value was assessed not by their value for the work they could produce, but by their inherent moral worth, is indicative to Zelizer (1985) of important cultural changes.

Whatever the ultimate sources of changes in family relationships and orientations to children-whether they reveal changes in cultural, structural, or demographic factors-there is some evidence that some changes in parental orientations to children are continuing. The above results suggest that parental orientations to the desired qualities of children increasingly reflect a desire for autonomy, and perhaps even more dramatically, decreasingly a desire for conformity to institutional demands. And, as noted in the preceding, these results are handsomely corroborated by similar findings from the Detroit, Michigan metropolitan area (Duncan et al., 1973, 1978; Alwin, 1984, 1986) and from Muncie, Indiana (Caplow and Chadwick, 1979; Bahr, 1980; Caplow et al., 1982; Alwin, 1988), all of which suggest movement away from an emphasis on obedience or conformity and toward one stressing autonomy or self-direction. It is not surprising, then, that our present results suggest continued movement in this direction.

The evidence for areas of the U.S. referred to above, which suggests continued changes in parental values over the greater part of the present century, is consistent with evidence from international sources as well. Trommsdorff (1983), for example, reports dramatic changes in Japan and West Germany in the amount of "independence" and "obedience" desired in children, which follow the same patterns described above. And, Alwin (1989a) reports evidence of birth cohort differences consistent with these patterns for Great Britain, West Germany, Australia, and Italy. Thus, evidence for social change in parental values beyond the present context is sufficiently great to strengthen the conclusions of the analysis presented above, which suggest that important changes have occurred over this century into the 1970s and 1980s. And, while the changes in the more recent time period, as witnessed above, may not be entirely uniform and may not be as easily detected over the relatively short span of time covered by the present investigation, these changes are sufficiently clear to warrant entertaining the explanations offered and the several factors considered here.

Even considering these factors, however, much of the change observed in the above indicators remains unexplained by the compositional factors 
considered here. Other structural or cultural factors, not easily assessed using the types of survey measures employed in this analysis, are undoubtedly responsible for many of these patterns. But whatever are the exogenous sources of the value changes witnessed here, their ultimate appreciation will require continued research using a variety of methods and data aimed at developing a more precise and complete picture of the flows of parental sentiment toward the behavioral qualities desired in children.

\section{APPENDIX}

TABLE A1

Mean Rankings of Child Qualities by Education of Parents with Children 0-17: NORC National Surveys, 1964, 1973-1975, 1976-1978, and 1980-1984

\begin{tabular}{lccccccccc}
\hline & \multicolumn{7}{c}{1964} \\
\cline { 2 - 9 } \multicolumn{1}{c}{ Characteristic } & $\begin{array}{c}\text { Less than } \\
\text { high school }\end{array}$ & $\begin{array}{c}\text { High } \\
\text { school }\end{array}$ & $\begin{array}{c}\text { Some } \\
\text { college }\end{array}$ & $\begin{array}{c}\text { College } \\
\text { grad }+\end{array}$ & Total & $\eta^{2}$ & $F$ & $p$ \\
\hline Good manners & 3.35 & 3.17 & 3.11 & 2.88 & 3.18 & .040 & 19.05 & 0.00 \\
Success & 2.79 & 2.60 & 2.62 & 2.77 & 2.70 & .010 & 4.52 & 0.00 \\
Honesty & 3.82 & 3.83 & 3.82 & 3.57 & 3.78 & .012 & 5.45 & 0.00 \\
Neat and clean & 2.84 & 2.75 & 2.67 & 2.31 & 2.70 & .040 & 18.86 & 0.00 \\
Good judgement & 3.03 & 3.03 & 3.02 & 3.08 & 3.04 & .001 & 0.19 & 0.90 \\
Self-control & 2.74 & 2.85 & 2.91 & 2.91 & 2.83 & .010 & 4.71 & 0.00 \\
Role conformity & 2.75 & 2.76 & 2.77 & 2.74 & 2.76 & .000 & 0.03 & 0.99 \\
Amicable & 3.15 & 3.20 & 3.20 & 3.30 & 3.20 & .004 & 1.88 & 0.13 \\
Obedience & 3.69 & 3.69 & 3.65 & 3.54 & 3.66 & .004 & 1.67 & 0.17 \\
Responsible & 2.72 & 2.67 & 2.89 & 3.01 & 2.79 & .024 & 11.14 & 0.00 \\
Considerate & 2.97 & 3.19 & 3.24 & 3.38 & 3.14 & .047 & 22.22 & 0.00 \\
Curiosity & 2.36 & 2.69 & 2.73 & 3.08 & 2.64 & .054 & 25.52 & 0.00 \\
Studious & 2.79 & 2.57 & 2.38 & 2.43 & 2.59 & .032 & 14.94 & 0.00 \\
$n$ & $(518)$ & $(350)$ & $(260)$ & $(227)$ & $(1355)$ & & & \\
\hline
\end{tabular}


TABLE A2

Mean Rankings of Child Qualities by Education of Parents with Children 0-17: NORC National Surveys, 1964, 1973-1975, 1976-1978, and 1980-1984

\begin{tabular}{lccccccccc}
\hline & & \multicolumn{7}{c}{$1973-1975$} \\
\cline { 2 - 7 } \multicolumn{1}{c}{ Characteristic } & $\begin{array}{c}\text { Less than } \\
\text { high school }\end{array}$ & $\begin{array}{c}\text { High } \\
\text { school }\end{array}$ & $\begin{array}{c}\text { Some } \\
\text { college }\end{array}$ & $\begin{array}{c}\text { College } \\
\text { grad }+\end{array}$ & Total & $\eta^{2}$ & $F$ & $p$ \\
\hline Good manners & 3.16 & 2.93 & 2.86 & 2.72 & 2.96 & .032 & 13.60 & 0.00 \\
Success & 2.85 & 2.75 & 2.83 & 2.87 & 2.81 & .004 & 1.76 & 0.15 \\
Honesty & 4.00 & 4.14 & 4.00 & 3.89 & 4.04 & .009 & 3.72 & 0.01 \\
Neat and clean & 2.68 & 2.54 & 2.37 & 2.22 & 2.52 & .036 & 15.58 & 0.00 \\
Good judgement & 3.31 & 3.52 & 3.59 & 3.78 & 3.50 & .029 & 12.29 & 0.00 \\
Self-control & 2.99 & 3.04 & 3.07 & 3.20 & 3.05 & .009 & 3.89 & 0.01 \\
Role conformity & 2.03 & 1.99 & 1.83 & 1.93 & 1.97 & .005 & 2.17 & 0.09 \\
Amicable & 2.93 & 2.97 & 2.96 & 3.00 & 2.96 & .001 & 0.48 & 0.70 \\
Obedience & 3.55 & 3.33 & 3.19 & 3.00 & 3.33 & .054 & 23.46 & 0.00 \\
Responsible & 3.16 & 3.38 & 3.48 & 3.59 & 3.36 & .039 & 16.63 & 0.00 \\
Considerate & 3.09 & 3.33 & 3.46 & 3.53 & 3.30 & .046 & 20.10 & 0.00 \\
Curiosity & 2.57 & 2.61 & 2.89 & 2.96 & 2.69 & .024 & 10.36 & 0.00 \\
Studious & 2.67 & 2.47 & 2.46 & 2.32 & 2.51 & .025 & 10.80 & 0.00 \\
$n$ & $(396)$ & $(474)$ & $(209)$ & $(167)$ & $(1246)$ & & & \\
\hline
\end{tabular}

TABLE A3

Mean Rankings of Child Qualities by Education of Parents with Children 0-17: NORC National Surveys, 1964, 1973-1975, 1976-1978, and 1980-1984

\begin{tabular}{lccccccccc}
\hline & \multicolumn{8}{c}{$1976-1978$} \\
\cline { 2 - 8 } \multicolumn{1}{c}{ Characteristic } & $\begin{array}{c}\text { Less than } \\
\text { high school }\end{array}$ & $\begin{array}{c}\text { High } \\
\text { school }\end{array}$ & $\begin{array}{c}\text { Some } \\
\text { college }\end{array}$ & $\begin{array}{c}\text { College } \\
\text { grad }+\end{array}$ & Total & $\eta^{2}$ & $F$ & $p$ \\
\hline Good manners & 3.16 & 2.93 & 2.93 & 2.64 & 2.95 & .041 & 16.61 & 0.00 \\
Success & 2.89 & 2.78 & 2.87 & 2.80 & 2.83 & .004 & 1.55 & 0.20 \\
Honesty & 4.00 & 4.10 & 4.08 & 3.83 & 4.03 & .012 & 4.58 & 0.00 \\
Neat and clean & 2.66 & 2.53 & 2.46 & 2.26 & 2.52 & .023 & 8.96 & 0.00 \\
Good judgement & 3.32 & 3.51 & 3.58 & 3.83 & 3.52 & .028 & 11.04 & 0.00 \\
Self-control & 2.92 & 3.08 & 3.16 & 3.13 & 3.06 & .018 & 7.01 & 0.00 \\
Role conformity & 1.90 & 1.89 & 1.90 & 1.83 & 1.89 & .001 & 0.22 & 0.88 \\
Amicable & 3.00 & 2.93 & 2.89 & 2.95 & 2.94 & .003 & 1.35 & 0.25 \\
Obedience & 3.60 & 3.38 & 3.25 & 3.11 & 3.38 & .040 & 16.34 & 0.00 \\
Responsible & 3.18 & 3.41 & 3.42 & 3.62 & 3.38 & .035 & 14.02 & 0.00 \\
Considerate & 3.14 & 3.31 & 3.35 & 3.48 & 3.29 & .025 & 10.07 & 0.00 \\
Curiosity & 2.56 & 2.63 & 2.74 & 2.96 & 2.68 & .018 & 7.17 & 0.00 \\
Studious & 2.68 & 2.51 & 2.38 & 2.54 & 2.54 & .019 & 7.61 & 0.00 \\
$n$ & $(323)$ & $(473)$ & $(201)$ & $(167)$ & $(1164)$ & & & \\
\hline
\end{tabular}


TABLE A4

Mean Rankings of Child Qualities by Education of Parents with Children 0-17: NORC National Surveys, 1964, 1973-1975, 1976-1978, and 1980-1984

\begin{tabular}{lccccccccc}
\hline & \multicolumn{7}{c}{$1980-1984$} \\
\cline { 2 - 9 } Characteristic & $\begin{array}{c}\text { Less than } \\
\text { high school }\end{array}$ & $\begin{array}{c}\text { High } \\
\text { school }\end{array}$ & $\begin{array}{c}\text { Some } \\
\text { college }\end{array}$ & $\begin{array}{c}\text { College } \\
\text { grad }+\end{array}$ & Total & $\eta^{2}$ & $F$ & $p$ \\
\hline Good manners & 3.30 & 3.04 & 2.87 & 2.86 & 3.04 & .041 & 18.27 & 0.00 \\
Success & 2.94 & 2.95 & 2.87 & 2.99 & 2.94 & .002 & 0.92 & 0.43 \\
Honesty & 3.96 & 4.06 & 4.03 & 3.96 & 4.01 & 00.3 & 1.28 & 0.28 \\
Neat and clean & 2.68 & 2.50 & 2.42 & 2.24 & 2.48 & .028 & 12.33 & 0.00 \\
Good judgement & 3.26 & 3.45 & 3.58 & 3.65 & 3.47 & .021 & 9.20 & 0.00 \\
Self-control & 2.97 & 3.00 & 3.03 & 3.02 & 3.00 & .001 & 0.54 & 0.66 \\
Role conformity & 1.91 & 1.82 & 1.73 & 1.71 & 1.81 & .007 & 2.82 & 0.04 \\
Amicablc & 2.95 & 2.95 & 2.96 & 2.94 & 2.95 & .000 & 0.04 & 0.99 \\
Obedience & 3.54 & 3.47 & 3.34 & 3.16 & 3.41 & .026 & 11.29 & 0.00 \\
Responsible & 3.16 & 3.33 & 3.39 & 3.67 & 3.36 & .051 & 22.59 & 0.00 \\
Considerate & 3.08 & 3.31 & 3.42 & 3.40 & 3.29 & .030 & 12.98 & 0.00 \\
Curiosity & 2.46 & 2.53 & 2.75 & 2.78 & 2.60 & .019 & 8.27 & 0.00 \\
Studious & 2.78 & 2.58 & 2.62 & 2.61 & 2.64 & .012 & 4.96 & 0.00 \\
$n$ & $(303)$ & $(500)$ & $(253)$ & $(218)$ & $(1274)$ & & & \\
\hline
\end{tabular}

TABLE A5

Mean Rankings of Child Qualities by Religio-Ethnic Background of Parents with Children 0-17: NORC National Surveys, 1964, 1973-1975,

$1976-1978$, and $1980-1984$

\begin{tabular}{|c|c|c|c|c|c|c|c|c|c|c|}
\hline \multirow[b]{2}{*}{ Characteristic } & \multicolumn{10}{|c|}{1964} \\
\hline & $A$ & $B$ & $C$ & $D$ & E & $F$ & Total & $\eta$ & $F$ & $p$ \\
\hline Good manners & 3.24 & 3.10 & 3.11 & 3.52 & 2.82 & 3.17 & 3.18 & .029 & 8.04 & .00 \\
\hline Success & 2.68 & 2.71 & 2.71 & 2.73 & 2.68 & 2.83 & 2.70 & .001 & 0.14 & .98 \\
\hline Honesty & 3.74 & 3.84 & 3.84 & 3.55 & 3.50 & 4.25 & 3.78 & .016 & 4.23 & .00 \\
\hline Neat and clean & 2.70 & 2.63 & 2.72 & 2.95 & 2.35 & 3.00 & 2.70 & .014 & 3.75 & .00 \\
\hline Good judgement & 3.00 & 3.07 & 3.00 & 3.09 & 3.21 & 3.25 & 3.04 & .003 & 0.71 & .62 \\
\hline Self-control & 2.82 & 2.84 & 2.89 & 2.72 & 2.82 & 2.58 & 2.83 & .005 & 1.34 & .24 \\
\hline Role conformity & 2.68 & 2.82 & 2.69 & 2.79 & 3.09 & 2.67 & 2.75 & .006 & 1.59 & .16 \\
\hline Amicable & 3.24 & 3.14 & 3.23 & 3.18 & 3.35 & 3.25 & 3.20 & .004 & 1.04 & .39 \\
\hline Obedience & 3.75 & 3.60 & 3.72 & 3.52 & 3.41 & 3.25 & 3.66 & .012 & 3.16 & .01 \\
\hline Responsible & 2.73 & 2.84 & 2.78 & 2.75 & 3.03 & 2.92 & 2.79 & .006 & 1.55 & .17 \\
\hline Considerate & 3.14 & 3.18 & 3.18 & 2.91 & 3.41 & 3.00 & 3.14 & .016 & 4.26 & .00 \\
\hline Curiosity & 2.69 & 2.68 & 2.56 & 2.54 & 2.82 & 2.00 & 2.64 & .007 & 1.78 & .11 \\
\hline Studious & 2.61 & 2.56 & 2.56 & 2.75 & 2.50 & 2.83 & 2.59 & .004 & 1.21 & .30 \\
\hline$n$ & (399) & (471) & (297) & (126) & (34) & (12) & (1339) & & & \\
\hline
\end{tabular}

$A$, Catholic; $B$, White non-Fundamentalist Protestant; $C$, White Fundamentalist Protestant; $D$, Black Protestant; $E$, Jewish; $F$, None. 
TABLE A6

Mean Rankings of Child Qualities by Religio-Ethnic Background of Parents with Children 0-17: NORC National Surveys. 1964, 1973-1975.

1976-1978, and 1980-1984

\begin{tabular}{lccccccccccc}
\hline & \multicolumn{10}{c}{} & \multicolumn{10}{c}{$1973-1975$} & & & & \\
\cline { 2 - 11 } \multicolumn{1}{c}{ Characteristic } & $A$ & $B$ & $C$ & $D$ & $E$ & $F$ & Total & $\eta^{2}$ & $F$ & $p$ \\
\hline Good manners & 2.96 & 2.90 & 2.86 & 3.45 & 2.75 & 3.33 & 2.97 & .041 & 10.54 & .00 \\
Success & 2.80 & 2.79 & 2.79 & 2.83 & 3.15 & 2.97 & 2.81 & .005 & 1.20 & .31 \\
Honesty & 3.99 & 4.12 & 4.14 & 3.72 & 4.00 & 4.10 & 4.05 & .018 & 4.50 & .00 \\
Neat and clean & 2.44 & 2.52 & 2.60 & 2.73 & 2.05 & 2.47 & 2.52 & .016 & 3.92 & .00 \\
Good judgement & 3.49 & 3.51 & 3.53 & 3.41 & 3.85 & 3.17 & 3.50 & .007 & 1.73 & .12 \\
Self-control & 3.01 & 3.06 & 3.10 & 3.03 & 3.05 & 3.20 & 3.05 & .004 & 0.95 & .45 \\
Role conformity & 1.97 & 1.97 & 1.90 & 2.06 & 1.75 & 2.23 & 1.97 & .004 & 1.12 & .35 \\
Amicable & 3.02 & 2.94 & 2.98 & 2.87 & 2.90 & 2.63 & 2.96 & .010 & 2.56 & .03 \\
Obedience & 3.31 & 3.28 & 3.34 & 3.58 & 2.90 & 3.43 & 3.33 & .016 & 4.08 & .00 \\
Responsible & 3.42 & 3.42 & 3.33 & 2.91 & 3.70 & 3.37 & 3.36 & .040 & 10.32 & .00 \\
Considerate & 3.32 & 3.38 & 3.26 & 3.02 & 3.55 & 3.07 & 3.30 & .022 & 5.52 & .00 \\
Curiosity & 2.70 & 2.64 & 2.71 & 2.70 & 3.00 & 2.67 & 2.69 & .002 & 0.63 & .68 \\
Studious & 2.55 & 2.47 & 2.45 & 2.69 & 2.35 & 2.37 & 2.50 & .010 & 2.59 & .02 \\
$n$ & $(342)$ & $(462)$ & $(264)$ & $(112)$ & $(20)$ & $(30)$ & $(1230)$ & & & \\
\hline & & & & & & & & & &
\end{tabular}

TABLE A7

Mean Rankings of Child Qualities by Religio-Ethnic Background of Parents with Children 0-17: NORC National Surveys, 1964, 1973-1975.

1976-1978, and 1980-1984

\begin{tabular}{|c|c|c|c|c|c|c|c|c|c|c|}
\hline \multirow[b]{2}{*}{ Characteristic } & \multicolumn{10}{|c|}{$1976-1978$} \\
\hline & $A$ & $B$ & $C$ & $D$ & $E$ & $F$ & Total & $\eta^{2}$ & $F$ & $p$ \\
\hline Good manners & 2.89 & 2.91 & 3.00 & 3.41 & 2.67 & 2.78 & 2.95 & .031 & 7.37 & .00 \\
\hline Success & 2.82 & 2.83 & 2.82 & 2.90 & 2.83 & 2.81 & 2.83 & .001 & .17 & .97 \\
\hline Honesty & 3.99 & 4.04 & 4.16 & 3.92 & 3.50 & 3.94 & 4.03 & .013 & 2.99 & 01 \\
\hline Neat and clean & 2.44 & 2.52 & 2.57 & 2.78 & 2.11 & 2.56 & 2.52 & .015 & 3.44 & .00 \\
\hline Good judgement & 3.53 & 3.58 & 3.44 & 3.22 & 4.22 & 3.50 & 3.51 & .019 & 4.34 & .00 \\
\hline Self-control & 3.05 & 3.08 & 3.08 & 2.93 & 2.94 & 3.06 & 3.06 & .004 & 0.91 & .48 \\
\hline Role conformity & 1.89 & 1.85 & 1.86 & 2.19 & 1.72 & 1.61 & 1.88 & .011 & 2.64 & .02 \\
\hline Amicable & 2.99 & 2.91 & 2.94 & 2.93 & 3.11 & 2.94 & 2.95 & .004 & 0.88 & .50 \\
\hline Obedience & 3.27 & 3.29 & 3.63 & 3.58 & 3.06 & 3.53 & 3.38 & .039 & 9.18 & .00 \\
\hline Responsible & 3.42 & 3.48 & 3.30 & 2.84 & 3.56 & 3.53 & 3.38 & .047 & 11.19 & .00 \\
\hline Considerate & 3.34 & 3.35 & 3.18 & 3.10 & 3.56 & 3.39 & 3.29 & .018 & 4.18 & .00 \\
\hline Curiosity & 2.79 & 2.68 & 2.51 & 2.57 & 3.22 & 2.81 & 2.68 & .017 & 3.96 & .00 \\
\hline Studious & 2.58 & 2.48 & 2.51 & 2.64 & 2.50 & 2.56 & 2.53 & .005 & 1.09 & .36 \\
\hline$n$ & (361) & $(400)$ & (250) & (83) & (18) & (36) & (1148) & & & \\
\hline
\end{tabular}


TABLE A8

Mean Rankings of Child Qualities by Religio-Ethnic Background of Parents with Children 0-17: NORC National Surveys, 1964, 1973-1975, 1976-1978, and 1980-1984

\begin{tabular}{lccccccccccc}
\hline & \multicolumn{10}{c}{$1980-1984$} \\
\cline { 2 - 10 } \multicolumn{1}{c}{ Characteristic } & $A$ & $B$ & $C$ & $D$ & $E$ & $F$ & Total & $\eta^{2}$ & $F$ & $p$ \\
\hline Good manners & 3.01 & 3.03 & 2.99 & 3.40 & 2.83 & 2.98 & 3.04 & .020 & 5.12 & .00 \\
Success & 2.94 & 2.93 & 2.90 & 3.06 & 3.09 & 2.78 & 2.94 & .005 & 1.22 & .30 \\
Honesty & 4.02 & 4.04 & 4.13 & 3.80 & 3.39 & 3.84 & 4.01 & .021 & 5.34 & .00 \\
Neat and clean & 2.44 & 2.45 & 2.54 & 2.74 & 1.83 & 2.47 & 2.48 & .022 & 5.54 & .00 \\
Good judgement & 3.47 & 3.52 & 3.42 & 3.20 & 4.09 & 3.63 & 3.47 & .019 & 4.80 & .00 \\
Self-control & 2.99 & 2.99 & 3.03 & 2.96 & 2.91 & 3.06 & 3.00 & .002 & 0.39 & .86 \\
Role conformity & 1.84 & 1.71 & 1.88 & 1.85 & 1.65 & 1.96 & 1.81 & .007 & 1.72 & .12 \\
Amicable & 3.02 & 2.94 & 2.94 & 2.91 & 3.00 & 2.76 & 2.95 & .009 & 2.33 & .04 \\
Obedience & 3.28 & 3.36 & 3.56 & 3.76 & 3.09 & 3.47 & 3.41 & .036 & 9.20 & .00 \\
Responsible & 3.41 & 3.41 & 3.28 & 3.05 & 3.78 & 3.41 & 3.36 & .028 & 7.11 & .00 \\
Considerate & 3.34 & 3.38 & 3.20 & 3.06 & 3.35 & 3.18 & 3.30 & .020 & 5.05 & .00 \\
Curiosity & 2.55 & 2.63 & 2.58 & 2.40 & 3.13 & 2.80 & 2.59 & .013 & 3.23 & .01 \\
Studious & 2.68 & 2.60 & 2.55 & 2.80 & 2.87 & 2.67 & 2.64 & .011 & 2.81 & .02 \\
$n$ & $(375)$ & $(425)$ & $(263)$ & $(113)$ & $(23)$ & $(49)$ & $(1248)$ & & & \\
\hline
\end{tabular}

\section{REFERENCES}

Alba, Richard D. (1976). "Social assimilation among American Catholic national-origin groups," American Sociological Review 41, 1030-1046.

Alba, Richard D. (1981). "The twilight of ethnicity among American Catholics of European ancestry," Annals of the American Academy of Political and Social Science 454, 8697.

Alwin, Duane F. (1984). "Trends in parental socialization values: Detroit, 1958-1983," American Journal of Sociology 90, 359-382.

Alwin, Duane F. (1986). "Religion and parental child-rearing orientations: evidence of a Catholic-Protestant convergence," American Journal of Sociology 92, 412-440.

Alwin, Duane F. (1988). "From obedience to autonomy: Changes in traits desired in children, 1924-1978," Public Opinion Quarterly 52, 33-52.

Alwin, Duane F. (1989a). "Historical changes in parental orientations to children," in Sociological Studies of Child Development (N. Mandell and S. Cahill, Eds.), JAI Press, Greenwich, CT, in press.

Alwin, Duane F. (1989b). "Social stratification, conditions of work and parental socialization values," in Social and Moral Values: Individual and Societal Perspectives (N. Eisenberg, J. Reykowski, and E. Staub, Eds.), Erlbaum, New York: in press.

Alwin, Duane F. (1989c). "Historical changes in sex differences in parental preferences for child qualities," unpublished manuscript, Institute for Social Research, University of Michigan.

Alwin, Duane F., and Jackson, David J. (1982a). "Adult values for children: An application of factor analysis to ranked preference data," in Social Structure and Behavior: Papers in Honor of William H. Sewell (R. M. Hauser, D. Mechanic, A. O. Haller, and T. S. Hauser, Eds.), pp. 311-329, Academic Press, New York.

Alwin, Duane F., and Jackson, David J. (1982b). "The statistical analysis of Kohn's measures of parental values," in Systems under Indirect Observation: Causality, Structure and Prediction (K. G. Jöreskog and H. Wold, Eds.), pp. 197-223, North-Holland, Amsterdam. 
Alwin, Duane F., and Krosnick, Jon A. (1985). "The measurement of values in surveys: A comparison of ratings and rankings," Public Opinion Quarterly 49, 535-552.

Bahr, Howard M. (1980). "Changes in family life in Middletown, 1924-1977," Public Opinion Quarterly 44, 35-52.

Bowles, Samuel, and Gintis, Herbert (1976). Schooling in Capitalist America: Educational Reform and the Contradictions of Fconomic Life, Basic Books, New York.

Bronfenbrenner, Urie (1979). The Ecology of Human Development: Experiments by Nature and Design, Harvard Univ. Press, Cambridge, MA.

Caplow, Theodore, Bahr, Howard M., Chadwick, Bruce A., Hill, Reuben, and Williamson, Margaret H. (1982). Middletown Families: Fifty Years of Change and Continuity, Univ. of Minnesota Press, Minneapolis, MN.

Caplow, Theodore, and Chadwick, Bruce A. (1979). "Inequality and life style in Middletown, 1920-78," Social Science Quarterly 60, 367-386.

Collins, Randall (1979). The Credential Society: An Historical Sociology of Education and Stratification, Academic Press, New York.

Duncan, Otis Dudley (1985). "Generations, cohorts, and conformity," in Cohort Analysis in Social Research (W. M. Mason and S. E. Fienberg, Eds.), pp. 289-321, Springer, New York.

Duncan, Beverly, Duncan, Otis Dudley, and McRae, James A., Jr. (1978). Sex Typing and Social Roles: A Research Report, Academic Press, New York.

Duncan, Otis Dudley, Schuman, Howard, and Duncan, Beverly (1973). Social Change in a Metropolitan Community, Russel Sage Foundation, New York.

Duvall, Evelyn M. (1946). "Conceptions of parenthood." American Journal of Sociology 52, 193-203.

Glenn, Norval D. (1988). "Social trends in the United States: Evidence from sample surveys," Public Opinion Quarterly 51, S109-S126.

Glenn, Norval D. (1977). Cohort Analysis, SAGE University Paper Series.

Glenn, Norval D. (1976). "Cohort analysts' futile quest: statistical attempts to separate age, period and cohort effects," American Sociological Review 41, 900-904, SAGE, Beverly Hills, CA.

Greeley, Andrew M. (1977). The American Catholic, Basic Books, New York.

Hout, Michael, and Greeley, Andrew M. (1987). "The center doesn't hold: Church attendance in the United States, 1940-1984," American Sociological Review 52, 325345.

Inkeles, Alex (1955) [1983]. "Social change and social character: The role of parental mediation," Journal of Social Issues 11, 12-23; Reprinted, Journal of Social Issues 39, $179-191$.

Inkeles, Alex (1984). "The responsiveness of family patterns to economic changes in the United States," The Tocqueville Review 6, 5-50.

Inkeles, Alex, and Smith, David H. (1974). Becoming Modern: Individual Change in Six Developing Countries, Harvard Univ. Press, Cambridge, MA.

Kohn, Melvin L. (1959). "Social class and parental values," American Journal of Sociology 64, 337-366.

Kohn, Melvin L. (1963). "Social class and parent-child relationships: An interpretation," American Journal of Sociology 68, 471-480.

Kohn, Melvin L. (1969). Class and Conformity: A Study in Values, Dorsey Press, Homewood. IL.

Kohn, Melvin L. (1976). "Social class and parental values: Another confirmation of the relationship," American Sociological Review 41, 538-545.

Kohn, Melvin L. (1977). "Reassessment 1977," in Class and Conformity: A Study in Values, 2nd ed., pp. xxv-lx, Univ. of Chicago Press, Chicago. 
Kohn, Melvin L. (1981). Personality, occupation, and social stratification: A frame of reference. in Research in Social Stratification and Mobility (D. J. Trieman and R. V. Robinson, Eds.), Vol. 1, pp. 267-297, JAI Press, Greenwich, CN.

Kohn, Melvin L., Schooler, Carmi, Miller, Joanne, Miller, Karen A., Work and Personality: An Inquiry into the Impact of Social Stratification, Schoenbach, Carrie, and Schoenberg, Ronald (1983), Ablex, Norwood, NJ.

Krosnick, Jon A., and Alwin, Duane F. (1987). "A cognitive theory of response-order effects in survey measurement," Public Opinion Quarterly 51, 201-219.

LeVine, Robert A., and White, Merry (1986). Human Conditions: The Cultural Basis for Educational Development, Routledge and Kegan Paul, London.

Lenski, Gerhard (1961). The Religious Factor: A Sociological Study of Religion's Impact on Politics, Economics and Family Life, Doubleday, Garden City, NY.

Lynd, Robert, and Lynd, Helen (1929). Middletown: A Study in Contemporary American Culture, Harcourt Brace, New York.

Maccoby, Eleanor E. (1978). "Current changes in the family and their impact upon the socialization of children," in Major Social Issues: A Multidisciplinary View (J. M. Yinger and S. J. Cutler, Eds.), Free Press, New York.

Mannheim, Karl (1952). "The problem of generations," in Essays on the Sociology of Knowledge (P. Kecskemeti, Ed.), pp. 276-320, Routledge and Kegal Paul, London.

Mason, Karen O., Mason, William M., Winsborough, Halliman H., and Poole, William K. (1973). "Some methodological issues in cohort analysis of archival data," American Sociological Review 38, 242-258.

Mason, William M., Mason, Karen O., and Winsborough, Halliman H. (1976). "Reply to Glenn," American Sociological Review 41, 904-905.

Mason, William M., and Fienberg Stephen E. (Eds.) (1985). Cohort Analysis in Social Research: Beyond the Identification Problem, Springer-Verlag, New York.

Miller, Karen A., Kohn, Melvin L., and Schooler, Carmi (1985). "Educational self-direction and the cognitive functioning of students," Social Forces 63, 923-944.

Miller, Karen A., Kohn, Melvin L., and Schooler, Carmi (1986). "Educational self-direction and personality," American Sociological Review 51, 372-390.

National Opinion Research Center (1988). General Social Surveys, 1972-87: Cumulative Codebook, Author, Chicago.

Pearlin, Leonard I., and Kohn, Melvin L. (1966). "Social class, occupation, and parental values: A cross-national study," American Sociological Review 31, 466-479.

Piaget, Jean (1932). The Moral Judgement of the Child, Free Press, New York.

Riley, Matilda White (1973). "Aging and cohort succession: Interpretations and misinterpretations," Public Opinion Quarterly 37, 35-49.

Rodgers, Willard L. (1982). "Estimable functions of age, period, and cohort effects," American Sociological Review 47, 774-787.

Ryder, Norman B. (1965). "The cohort as a concept in the study of social change," American Sociological Review 30, 843-861.

Schaeffer, Nora C. (1982). "A general social survey experiment in generic words," Public Opinion Quarterly 46, 572-81.

Schlumbohm, Jurgen (1980). " 'Traditional' collectivity and 'modern' individuality: Some questions and suggestions for the historical study of socialization: The examples of the German lower and upper bourgeoisie around 1800," Social History 5, 71-103.

Schooler, Carmi (1976). "Serfdom's legacy: An ethnic continuum," American Journal of Sociology 81, 1265-1286.

Smith, Herbert L., Mason, William M., and Fienberg, Stephen E. (1982). "More chimeras of the age-period-cohort accounting framework: Comment on Rodgers," American Sociological Review 47, 787-793. 
Stone, Lawrence (1977). The Family, Sex and Marriage in England 1500-1800, Harper and Row, New York.

Thornton, Arland (1988). "Changing attitudes toward family issues in the United States," Unpublished paper, Institute for Social Research, Ann Arbor.

Thornton, Arland and Fricke, Thomas E. (1987). "Social change and the family: comparative perspectives from the West, China, and South Asia," Sociological Forum 2. 746-779.

Thornton, Arland, and Freedman, Deborah (1983). "The changing American family," Population Bulletin 38, 4, Population Reference Bureau, Washington, DC.

Trommsdorff, Gisela (1983). "Value change in Japan," International Journal of Intercultural Relations 7, 337-360.

Vinovskis, Maris A. (1987). "Historical perspectives on the development of the family and parent-child interactions," in Parenting across the Life Span: Biosocial Dimensions (Jane B. Lancaster, Jeanne Altmann, Alice S. Rossi, Lonnie R. Sherrod, Eds.), pp. 295-312, Aldine De Gruyter, New York.

Weil, Frederick D. (1987). "Cohorts, regimes, and the legitimization of democracy: West Germany since 1945," American Sociological Review 52, 308-324.

Wright, James D., and Wright, Sonia R. (1976). "Social class and parental values for children: A partial replication and extension of the Kohn thesis," American Sociological Review 41, 527-537.

Yankelovich, Daniel (1984). "American values: Change and stability," Public Opinion, Dec/Jan, 2-8.

Zelizer, Viviana A. (1985). Pricing the Priceless Child: The Changing Social Value of Children, Basic Books, New York. 